\title{
Inclusiveness in Street Network of City Centre - Case Studies: 15-Khordad, Berlan and Sepah-Salar Pedestrian-based Axes in Central Tehran
}

\author{
Sanaz Shobeiri \\ School of Natural and Built Environment, Queen's University Belfast, United Kingdom \\ *Corresponding Author: S.Shobeir@qub.ac.uk \\ Received October 13, 2020; Revised January 26, 2021; Accepted February 17, 2021
}

\section{Cite This Paper in the following Citation Styles}

(a): [1] Sanaz Shobeiri, "Inclusiveness in Street Network of City Centre - Case Studies: 15-Khordad, Berlan and Sepah-Salar Pedestrian-based Axes in Central Tehran," Environment and Ecology Research, Vol. 9, No. 1, pp. 1 - 29, 2021. DOI: 10.13189/eer.2021.090101.

(b): Sanaz Shobeiri (2021). Inclusiveness in Street Network of City Centre - Case Studies: 15-Khordad, Berlan and Sepah-Salar Pedestrian-based Axes in Central Tehran. Environment and Ecology Research, 9(1), 1 - 29. DOI: 10.13189/eer.2021.090101.

Copyright $\bigcirc 2021$ by authors, all rights reserved. Authors agree that this article remains permanently open access under the terms of the Creative Commons Attribution License 4.0 International License

\begin{abstract}
Today, one of the most growing discourses in design and planning City Centres worldwide is inclusiveness. Identification of major and minor groups of users thus forms a primary step to achieve an inclusive City Centre. To this end, this paper investigates Central Tehran and its network of street with a focus on three "shoppingrecreational-pedestrian"-based paths called 15-Khordad Street, Berlan Alley and Sepah-Salar Street. The reason for this selection is their ongoing revived or remaining presence of pedestrians despite the prevailing vehicle domination in Tehran's City Centre. In this research, scale (mental and spatial), age and gender, and speed (accessibility and mobility) have been considered to individually and collectively study the concept of inclusiveness in the three case studies. Accordingly, this comparative study depicts how divergently and similarly, the streets of Central Tehran can fully respond to the expectations of various age-gender groups of Tehranians. The applied methodology incorporates the literature review, direct appraisal, photography, and dot-based analysis. For this qualitative-quantitative study, direct observation has been carried out in three consecutive week days in September 2019 from 10 a.m. to 4 p.m. to cover all potential effects of time on presence of users. Despite the short lengths of $15-\operatorname{Khordad}(2.8 \mathrm{~km})$, Berlan $(1.2 \mathrm{~km})$, and Sepah-Salar $(0.5 \mathrm{~km})$, these paths can significantly contribute to revitalisation of the physical, mental and spiritual connectivity of Tehranians with their City Centre.
\end{abstract}

As a result, this paper aims to elucidate the potentials and problems to realise this reconciliation in an all-embracing sense.

Keywords Inclusiveness, City Centre, Age, Gender, Pedestrian, Tehran, Street

\section{Introduction}

As a result of the accelerating speed of the presence of automobiles in the current urban contexts worldwide, the big cities - and in particular the metropolises and megalopolises - have faced serious challenges about the presence of pedestrians in urban spaces. This trend started to appear as an outcome of the industrial revolution and the modernisation process. Consequently, this trend led to manifestation of a turning point with an increasing momentum of changes in urban platforms in the history of mankind. For decades, and as a result of the growing number of cars in urban context, the human scale has been neglected and disregarded. This has then resulted in low-to-high disappearance of pedestrians and public life in public spaces.

The global awareness of the fading of pedestrians, however, has resulted in recent ongoing global efforts for a revival of the human scale particularly in the recent 
decades. The word "recent" here, implies on a range of one-to-six decades depending on the context, the magnitude of the problem, and the acknowledge of this necessity. This revival is crucial to achieve a lively, safe, healthy, inclusively, and sustainable cities. This re-integration of the human scale with design and planning of cities would thus create a balance in the spectrum of scales in urban contexts [1-5].

This paper mainly studies the current situation of pedestrians in urban spaces of the case study Tehran. With a focus on the city centre and the streets with the recreational-shopping purposes, this research aims to investigate the interconnection of age and gender with three different-scale streets in Central Tehran. In other words, this paper, simultaneously studies the various age-gender groups, their preferred and not-preferred activities, and the existing different-scale 'shoppingrecreational-pedestrian'-oriented streets as a key category of public spaces of the city centre of Tehran.

In short, this paper qualitatively and quantitatively focuses on the neglected aspects of inclusiveness that threaten the physical, mental and spiritual attachments of general citizens to the shopping-recreationalpedestrian'-based streets of their city centre. This is principally associated with the indicators of the age-gender and speed (accessibility and mobility). To this end, the researcher has tried to explore the city centre in the same way as the general users. In other words, this paper goes beyond the on-desk review of any short-to-long executive programs - proposed and/or implemented by practical institutions such as Municipality of Tehran - by evaluating the current situation of the city centre and analysing the ongoing quality of the users' experiences in its shopping-recreationalpedestrian'-based streets.

\section{Methodology}

In order to study the mutual influence of age and gender indicators and spatial features of different-scale streets, an incorporated methodology is applied in this research. This mainly includes the literature review, direct observation, photography and dot-based analysis. With a focus on the three latter methods, this paper mainly aims to study the current situation of Tehran's city centre particularly its 'shopping-recreational-pedestrian'-based streets and their divergent groups of users. Further details on how these methods contribute to the investigation of the present condition of these streets are explained in this section (section 2).

\subsection{Literature Review and Related Analysis}

Literature review and its critical evaluation in different stages of a research is carried out to provide an in-depth information on the context and background of the study. As a requisite method for the principal method of direct observation, literature review provides selective details about the history of the subject of study consisting of Tehran, particularly the city centre and its pedestrian-based streets [6,7]. As further explained by Hart [7] in 2018:

A review of the literature is important because without it you will not acquire an understanding of your topic, know what has already been done on it, understand how it has been researched or grasp what the key issues are that need addressing [7, pp.2-3].

Literature review in this research is a critical evaluation of the ongoing as well as the previous situation of the streets. In other words, the review of the literature about the process of changes in the area of city centre - from past to present - provides a detailed information on the context and background of the study. This would thus clarify the specific aspects that have shaped or affected the spatial features of the streets in Central Tehran. Reviewing the literature also elucidates the features that have been gradually or drastically faded and thus need to be revived in order to restore the human scale in public spaces of Central Tehran.

\subsection{Direct Observation}

Direct observation, as a naturalistic method, is applied in this research to study the non-interfered status of three different-scale "shopping-recreational-pedestrian"-based streets in the city centre of Tehran. Watching with care on the ordinary scenes of people's ongoing activities in Tehran's city centre provides an elaborate understanding of current preferences and dislikes of Tehranian users as well as the potentials and problems of these three-scale streets. In each of the three case studies of this paper, this method has been carried out in September 2019 in a common day in the morning as well as in the afternoon (10 a.m. -4 p.m.).

As further explained by Gehl and Svarre [1] in 2013:

Public life changes constantly in the course of a day, week, or month, and over the years. In addition, design, gender, age, financial resources, culture and many other factors determine how we use or do not use public space. There are many excellent reasons why it is difficult to incorporate the diverse nature of public life into architecture and urban planning. Nonetheless, it is essential if we are to create worthy surroundings for the billions of people who daily make their way between buildings in cities around the world. In this context, public space is understood as streets, alleys, buildings, squares, bollards: everything that can be considered part of the built environment [1, p.2].

In short, in order to study streets as one category of the 
public spaces, it is necessary to investigate their ongoing public life during different hours of a day. Hence, in the three case study streets of this research, direct observation has been carried out in September 2019 in three consecutive week days from morning to afternoon.

\subsection{Photography}

In order to study the groups of users through the direct observation in this research, photo taking and dot-based analysis of the non-interfered situations of the streets have been applied throughout the whole lengths of paths. The number of the photos taken in each street was deliberately defined as non-predetermined in order to allow the researcher to experience the streets in a similar way of the common users. In other words, the photos were taken while passing these streets to cover almost all existing varieties in and alongside their tracks.

As further explained by Langmann and Pick [8] in 2018 about photography in social research, the reasons for employing photography in social research can be significantly various. The two examples of "the discovery and understanding of contextual social circumstances and structures of people to its use as a theoretical vehicle for practical change" $[8, p .6]$ outlined by Langmann and Pick [8], best represent the possible wide range of using photography in researches engaged in public and social topics. In this research, photographs and photographic truths can be identified as a gateway to tell a story about the current situation of the studied area and their general users.

Following the philosophic trend about photography by Henri Cartier-Bresson (1098-2004) - the French documentary photographer who is characterised as the father of photojournalism - a photograph represents a reportage. As a result, through the photography in the direct observation of this research, the researcher's (photographer's) ability, or more precisely, the responsibility, is to re-tell a report on the real world. As quoted by Cartier-Bresson, in this process, "your eye must see a composition or an expression that life itself offers you, and you must know with intuition when to click the camera" [9]. The phrase "real world", in this paper, refers to the non-inferred and ordinary scene of daily life of Tehranians in the city centre of Tehran, particularly in the three case study streets.

\subsection{Dot-based Analysis}

In investigating the daily routines of Tehranians in streets of Central Tehran, the other complementary applied method for analysing the captured photos is a dot-based system. In this system, each category of users is specified with a particular colour. The numbers of each category of dots (users) have been then counted and inserted to the software of Excel for further detailed analysis. In other words, an integrated qualitative-quantitative analysis in this research clarifies the major and minor groups of users as well as their ratios. This would thus be helpful to highlight the aspects that need to be prioritised while proposing the design and planning strategies for the streets of Central Tehran.

In this research, two sets of dot-based qualitative-quantitative analysis have been carried out. The first is based on the gender and age. The identified sub-groups in this set are 1) woman; 2) man; 3) child, 4) woman in car/on motor; 5) man in car/on motor; 6) child in car/on motor; and 7) car/motor. The second set of analysis is based on speed and automobile usage in Central Tehran. The sub-groups in this set include: 1) pedestrian/on foot; 2) car/motor; and 3) In car/on motor. The overall analysis of the three case study streets about the two sets of sub-groups would provide the opportunity of comparative as well as individual investigations about different-scale streets. The following diagram (Figure 1) best summarises how the methodology of this paper contributes to the main aim of this investigation.

\section{The Context of Study: Tehran and the City Centre}

Tehran has been the capital of Iran since 1794. Since then, it has experienced three historical eras. These include: 1) the Qajar dynasty (1794-1925); 2) the Pahlavi dynasty (1925-1979); and 3) the Islamic Republic (1979present). Throughout these years, the entire area of the city has undergone constant development. The structural and spatial changes to Tehran, particularly since the city became the capital, have resulted in the transformation of an enclosed city with the population of 15,000 in 1794 to an ever-growing metropolis or megalopolis ${ }^{1}$ with a provincial population of 13 million in 2017 and around 10 million just in the city of Tehran [3,10-14].

In other words, the capital as a ramparted city in 1794 has been transformed into an ever-developing and ever-expanding city at the present time. Tehran province comprises around 17 percent of the whole population of the country [3,10-14]. The following two diagrams illustrate further details of the key dynasties as well as the kings who promoted changes in Tehran, in the process of the city's development and expansion. 


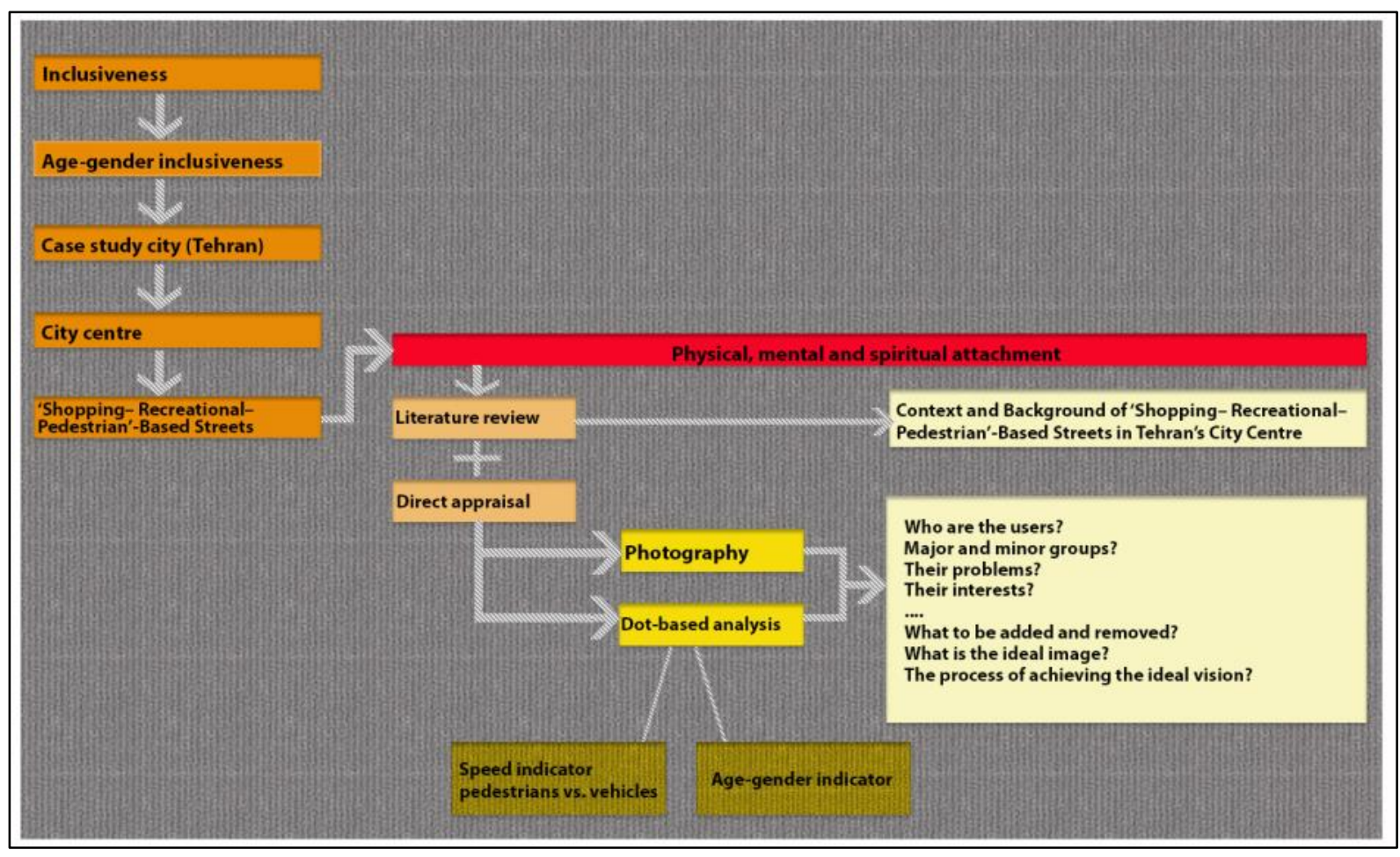

Figure 1. Methodology and its integration with the research aim and process (Source: Author, 2020)

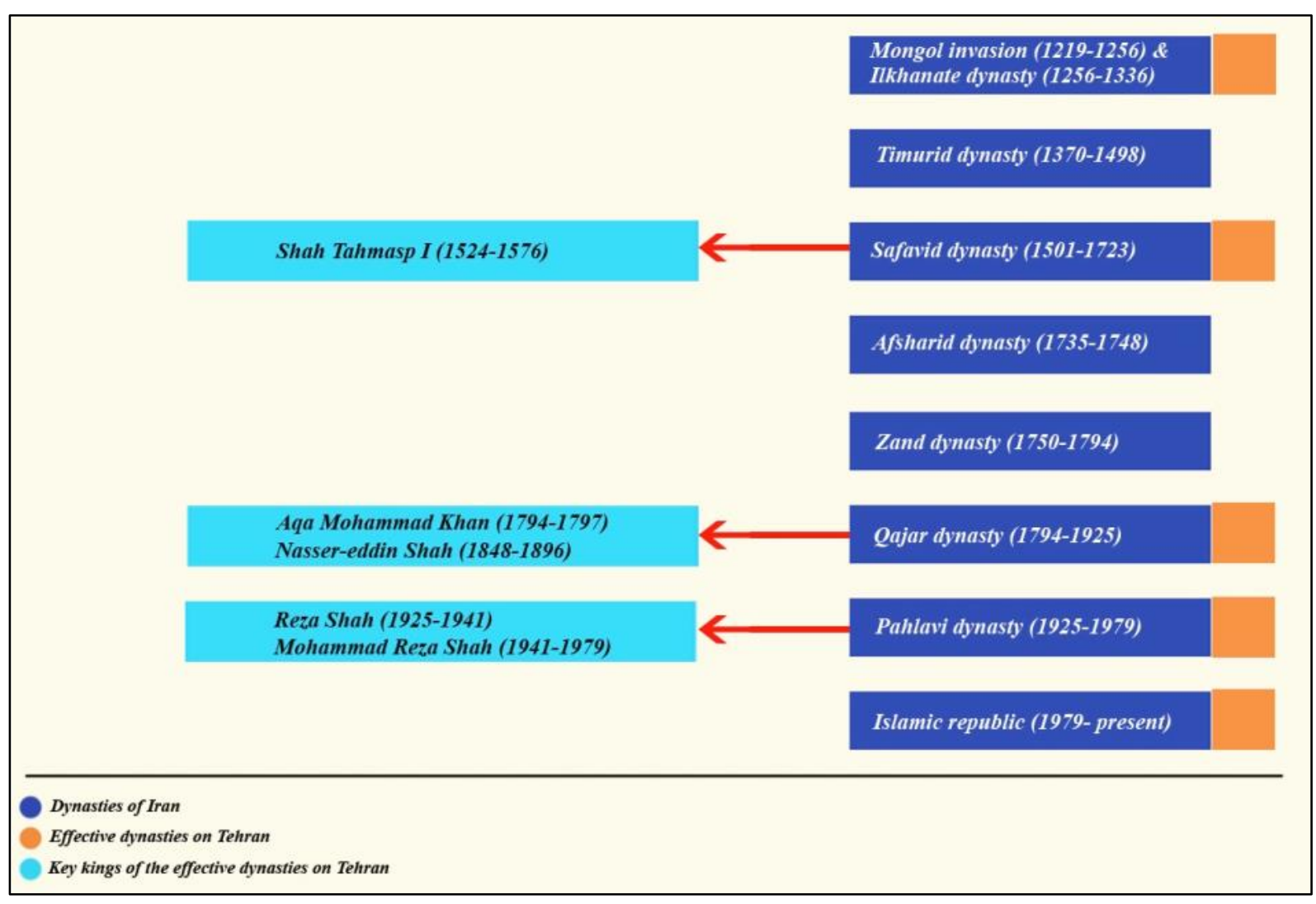




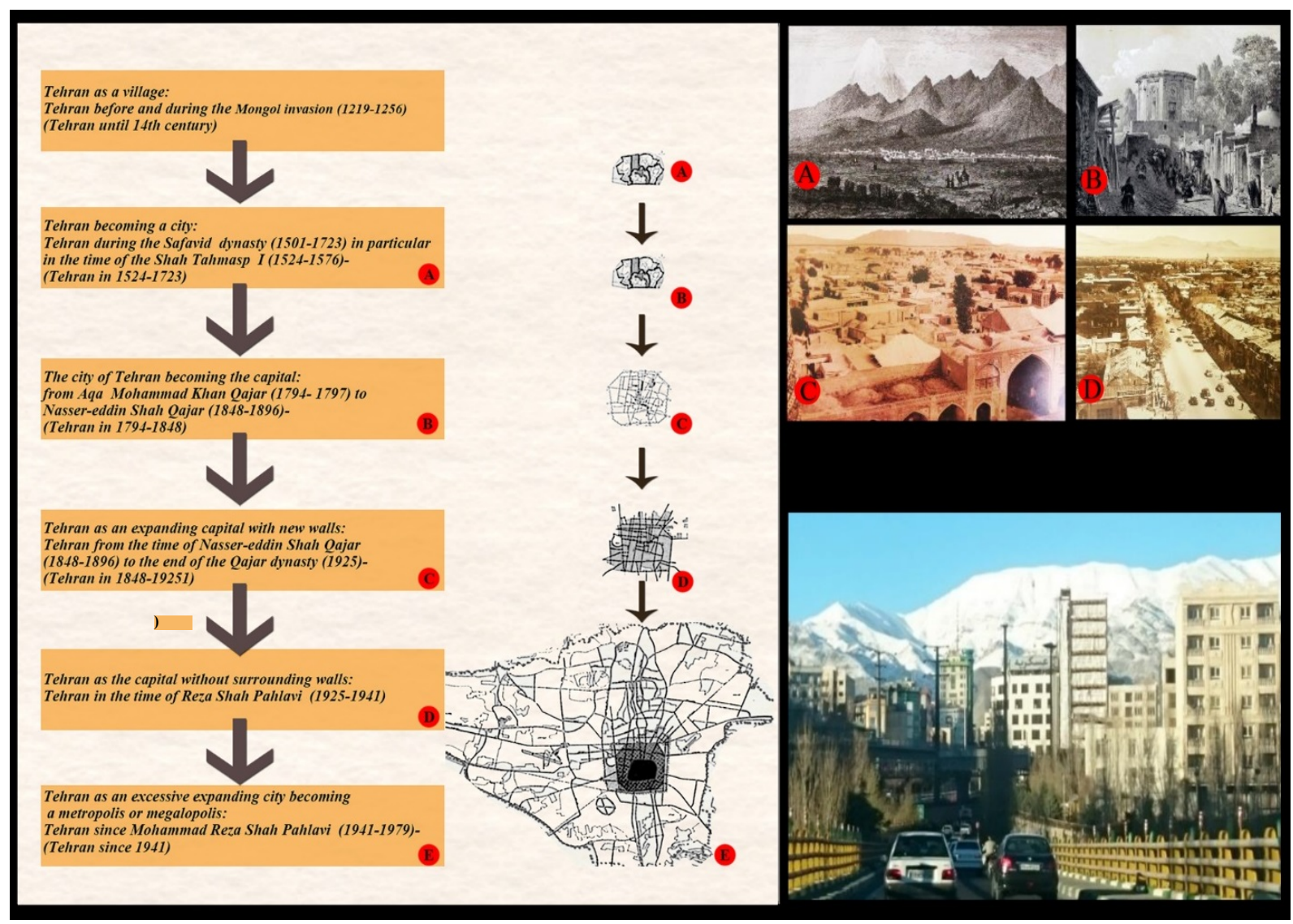

Figure 2. (Top) The dynasties and kings that helped to bring about changes in Tehran (Source: Author, 2016). The applied sources for providing this diagram are Refs. [3,11,13,15-18]. It should be noted that during the years of the Afsharid and Zand dynasties there were minor changes to various resources. However, the most noted dates are applied in the diagram; (bottom) Tehran and its developments and expansion, and related images (Source of the maps: Refs. [3,11,13]; Source of the applied dates: Refs. [3,11,13,15-18]; Source of the old images: Refs. [11,19-22]; Source of the bottom-right image (current situation): Author, 2016)

As shown in Figure 2 above, Tehran became recognised as the capital by the first king of Qajar dynasty called Aqa Mohammad Khan Qajar in 1794. The changes to Tehran since it became the capital during the Qajar dynasty can be categorised into two sections: 1) Tehran from Aqa Mohammad Khan Qajar (1794-1797) to Nasser-eddin Shah Qajar (1848-1896) (Tehran in 1794-1848); and 2) Tehran from the time of Nasser-eddin Shah Qajar (1848$1896)$ to the end of the Qajar dynasty (1925) (Tehran in 1848-1925). In the section 2 of Qajar dynasty, Tehran converted to an expanding capital with new walls $[3,11,13,16]$.

In most current literature about Tehran, what is recognised as 'Old Tehran' mainly refers to Tehran in the times of Safavid (1501-1723), Afsharid (1735-1748), Zand (1750-1794) and Qajar in the period 1 (1794-1848) dynasties. In other words, the term 'Old Tehran' addresses Tehran from 1501 to 1848 . The reason is that in the time of Nasser-eddin Shah Qajar, the effects of Western designs, and in particular French styles, started to appear in the designs of various functions of the city. This was a result of the presence of European architects in Iran and, simultaneously, the return of Iranian-educated architects and engineers from Europe, in particular from France $[3,11,13,16]$.

As further explained by Banimasoud [16] in 2009, until the middle of the reign of Nasser-eddin Shah Qajar, Tehran was recognised as a city with Iranian-Islamic features. From the middle of the reign of Nasser-eddin Shah Qajar onwards, as a result of the emergence of some Western indications, Tehran experienced a cultural eclecticism. Hence, while the old part of the city mainly kept its traditional characteristics in its design, the developing parts of the city developed with more European and Western characteristics $[3,11,13,16]$. One of the platforms that represent cultural eclecticism in urban context, is the network of streets and squares. The point is further explained in the following section.

It should be noted that, in majority of academic references, what is recognised as Tehran's 'City Centre' nowadays is the area of Tehran in the time of the king Pahlavi I particularly in 1937-1941. Tehran of 1937-1941, strongly overlaid, or more precisely, substituted the ramparted Tehran with many signs of cultural eclecticism remaining from the section 2 of Qajar dynasty (18481925), in particular from the time of the king time of 
Nasser-eddin Shah Qajar (1848-1896). Although the approximate periphery of these two periods is almost the same, the structural and fundamental changes have completely changed the essence and meaning of the area. The spontaneous streets network for instance, which, was of the human-scale platform for presence of Tehranians, got converted into an automobile-dominated irregular grid network of transport vessels $[3,16]$.

\section{The Background of 'Shopping- Recreational-Pedestrian'-Based Streets in Tehran's City Centre: Streets in the Style of Tehran (Nasseri)}

A pattern of street that significantly developed in the time of Nasser-eddin Shah Qajar was called the Tehran or Nasseri style. This is recognised as a style of street that represents the characteristics of its own time, the Nasser-eddin Shah Qajar and his reign. In the time of Nasser-eddin Shah Qajar (1848-1896), there was a cultural eclecticism that was reflected in the spatial design of Tehran. The co-presence of traditionalist and modernist points of view created an 'in-between' phase in the design of Tehran, and in particular in the urban spaces. In the streets designed in the Nasseri style, for instance, the 'in-between' characteristics are visible. The streets of the Nasseri style obey two formats, including the Isfahan style and the pattern of European streets from the industrial age of France [3,16,23].

As shown in Figure 3, streets in the style of Isfahan had streams and rows of planted trees on both sides. Single buildings allocated in the middle of garden formed the sides of these streets. Water from these streams was mainly related to the Qanats ${ }^{2}$ of Tehran in the time of Qajar, in particular in the time of Nasser-eddin Shah Qajar [23-25]. Qanat was as an Iranian water-based structure with the history of around 6,000 years that was used for water provision and irrigation [23-25].

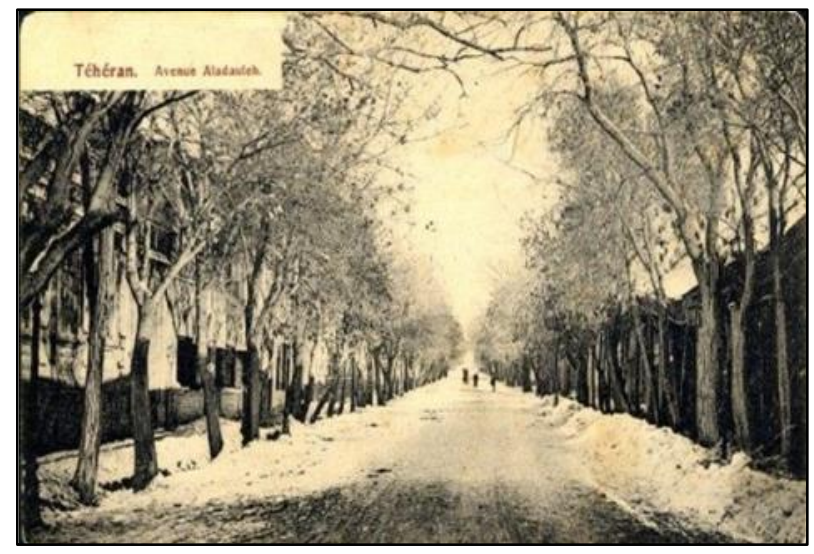

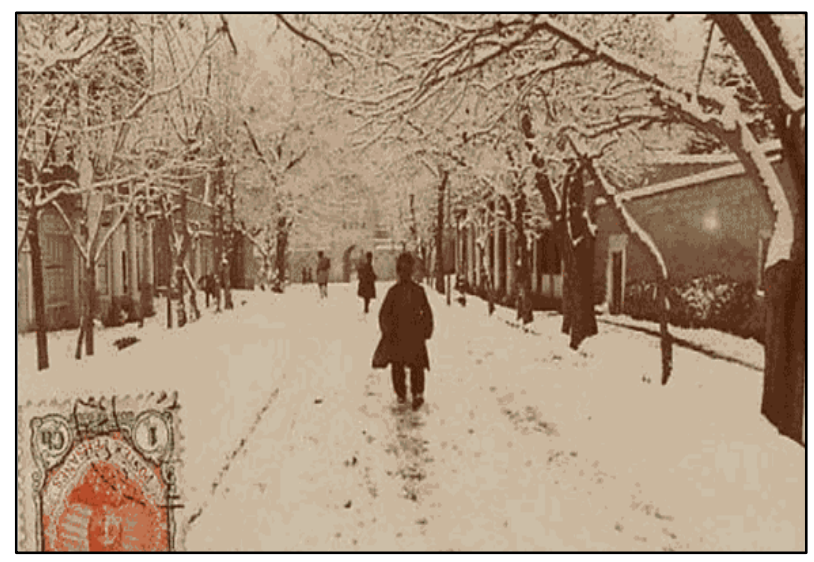

Figure 3. Alaoddoleh Street ${ }^{3}$ in Tehran in 1910: an example of a street in the style of Isfahan in Tehran (Source: Ref. [26])

The streets in the Nasseri style were neither as recreational as the streets of the Isfahan pattern in Isfahan nor as access-based as the streets of modernised Tehran in later times. Rather, these streets were recognised as live urban spaces with identities that were representative of the Iranian-made modernity of the Qajar dynasty, in particular in the time of Nasser-eddin Shah Qajar [23-27]. One of these streets, called Bab-e-Homayoon ${ }^{4}$ is exemplified in Figure 4 to further clarify this point.

Bab-e-Homayoon Street was the first street of Tehran in which trees were planted in a linear path on sides. This street was recognised as one of the most significant streets in Tehran, in particular in the time of Nasser-eddin Shah Qajar. This street had two rows of unified-style stores, and rows of streams and trees on both sides. While the rows of stores in the design of this street obeyed the industrial-age French style that provided the urban functions, the rows of trees and streams, and the arch-shaped vault in the design of the stores obeyed the recreational aspect of the Iranian style $[3,16,26,27]$.

The eclecticism was not merely confined to the design of this street. Rather, it played an important role in the activities of everyday life and specific days. While Tehranians used this street as a recreational urban space in summers, the street was used for trading and shopping purposes in everyday life. Bab-e-Homayoon Street was also used for illumination and fireworks on specific days such as the Persian New Year (Norouz ${ }^{5}$ ). Furthermore, the street was recognised as a key access path of the royal family to specific royal buildings in this street and in its neighbourhood. All of these usages show the eclecticism that resulted in the integration of recreational, commercial, social, cultural and connecting roles of the street in the style of Nasseri [3,16,27,28]. Figure 4 illustrates further details of Bab-e-Homayoun street and its Nasseri style features. 

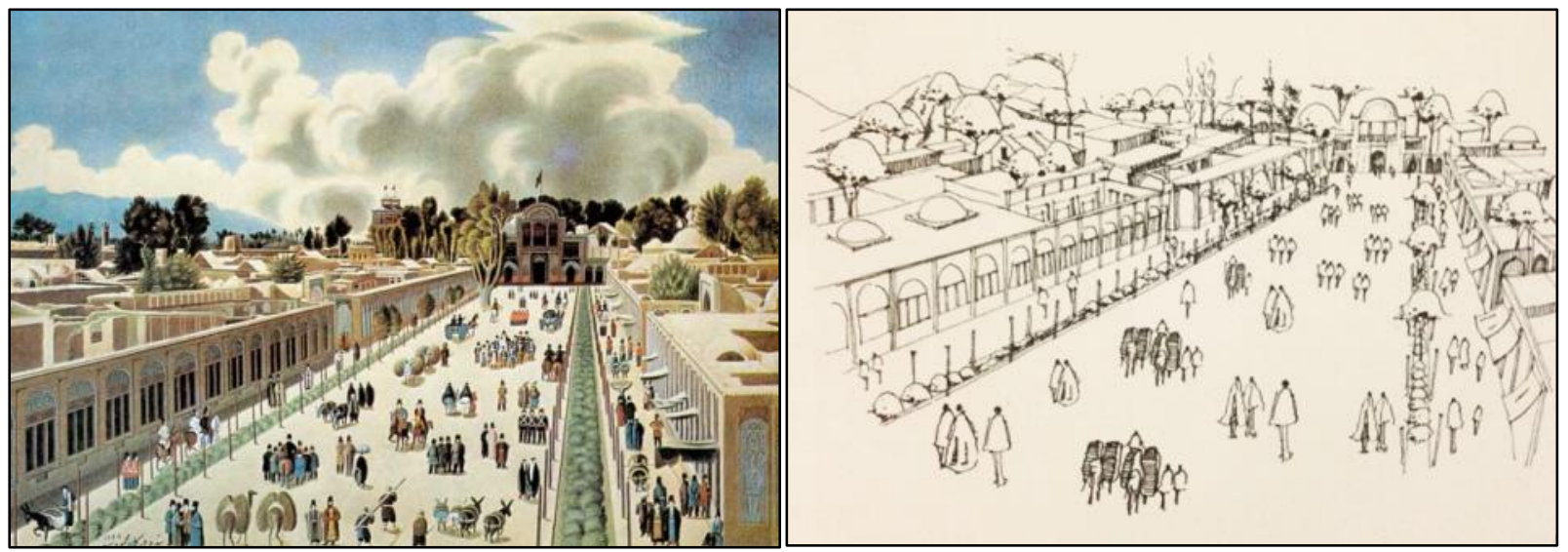

Figure 4. Bab-e-Homayoon Street as an example of a street in the style of Nasseri: (left) painting by Mahmudkhan Malek-ol-Shoara (Source: Re. [29]); (right) sketch by Zaka and Semsar (Source: Refs. [3,30])
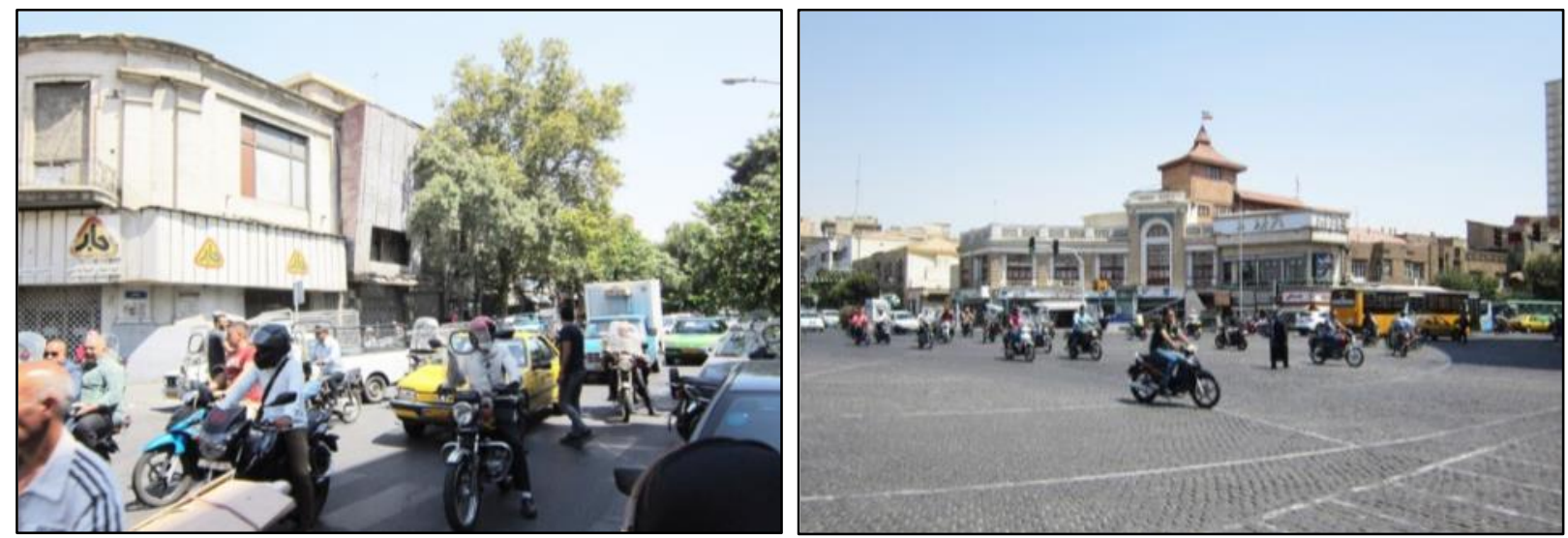

Figure 5. Vehicle orientation in the City Centre of Tehran - chaotic movements and interferences of pedestrians, cars, motorcycles and buses in squares and streets of Central Tehran (source: Author 2019)

\section{Revival of 'Shopping-Recreational- Pedestrian'-Based Streets in the Current City Centre of Tehran}

The octagonal fortifications of the city - associated to the time of Nasser-eddin Shah Qajar- were later demolished between 1932 and 1937 and the surrounding moat was filled in the time of the king Reza Shah Pahlavi, also known as the king Pahlavi I (1925-1941). In the time of King Reza Shah Pahlavi (1925-1941), and as a result of the political, social and economic transformation, Tehran transitioned into an administrative-industrial society. Since then, Tehran started to grow and transform into an urban conurbation through an ever-developing and unlimited construction $[3,11,13]$.

In the process of these fundamental changes in the spatial structure of the city - shaped under the effects of the international movement of modernism - Tehran was organised in a grid pattern with streets of straight axes. In other words, the organic, irregular and spontaneous design of the city was converted into a regular grid network of streets and buildings with potential for expansion in all directions. Furthermore, the automobile entered the streets of Iran, and in particular to Tehran, in 1902 in the time of King Mozaffareddin-Shah Qajar (in the late Qajar dynasty). The accelerating momentum - which was a main outcome of the entrance of automobiles in 1902 and the transformation of Tehran into an administrative-industrial society in the time of King Reza Shah Pahlavi (1925-1941) - led to the transformation in the designs of public spaces, and in particular the network of squares and streets $[3,16,31]$.

As a result of the excessive and ever-expanding development of Tehran in particular since 1937, the organic and spontaneous design of the urban context of Tehran was substituted with a grid of regular and irregular networks of streets, in an automobile-based system. As also presented in Figure 5, this has resulted in allocating the priority to automobiles and subsequently the significant fading of the presence of pedestrians in urban spaces particularly in streets and squares. The intensity of this challenge, however, is more in the City Centre of Tehran. The reason is that the City Centre, as a core of development and expansion of city, was the primary platform to experience the changes and thus to represent the novel concepts $[3,5,13]$. 
In the recent few decades and specifically in the last fifteen years, re-prioritising the human scale in urban spaces of Tehran has come to consideration in large-scale design and planning for Tehran. In comprehensive plan for Tehran in 2007 by the Ministry of Housing and Urban Development, for instance, the traces of this upward trend could be found. Furthermore, the acknowledgement of pedestrians and human scale can be easily found while considering the official guidelines by this ministry. It should be noted that the current Ministry of roads and Urban Development is an incorporation of two former ministries as the Ministry of Housing and Urban Development of Iran, and the Ministry of Roads and Transportation got merged in 2011.

In the book of Design Guidance for Urban Spaces of Iran in 2008 by the Urban Planning and Architecture Vice-Directorate of this ministry [32], for instance, it is stated that the need for the presence of high-speed paths is inevitable in urban context in Iran; however, caution is strongly required to keep the life of urban spaces. In other words, urban streets as transit paths need to be defined in an organised system, particularly in a way that doesn't hurt the city's life and interwoven network of urban life. The importance of pedestrians becomes further obvious while appreciating that the social interactions mainly take place between the pedestrians rather than in vehicular transports. This acknowledgement has thus resulted in the revival of the concept of pedestrian-based streets in Tehran, specifically in the City Centre. The point is further discussed in the following sections of this paper.

\section{Introduction of the Three Case Studies of 'Shopping-Recreational- Pedestrian'-Based Streets: 15-Khordad Street, Sepah-Salar Street, and Berlan Alley}

As presented in the map below (Figure 6), 15-Khordad Street is located between the area of Golestan palace (royal citadel or Arq) and Grand Bazaar of Tehran. The whole $2.8 \mathrm{~km}$ length of this street is extended between the two streets called Vahdat-e-Eslami and Rey. In this 2.8 $\mathrm{km}$, the length of around $1 \mathrm{~km}$ has been recently defined as car-free recreational path. This pedestrian-oriented path is mainly located between the Galubandak Crossroads (intersection of 15-Khordad Street and Khayyam Street) and Mostafa Khomeini Street. It should be noted that the process of pedestrianisation of this street has been implemented by Municipality of the District 12 of Tehran in 2015 [5,33].

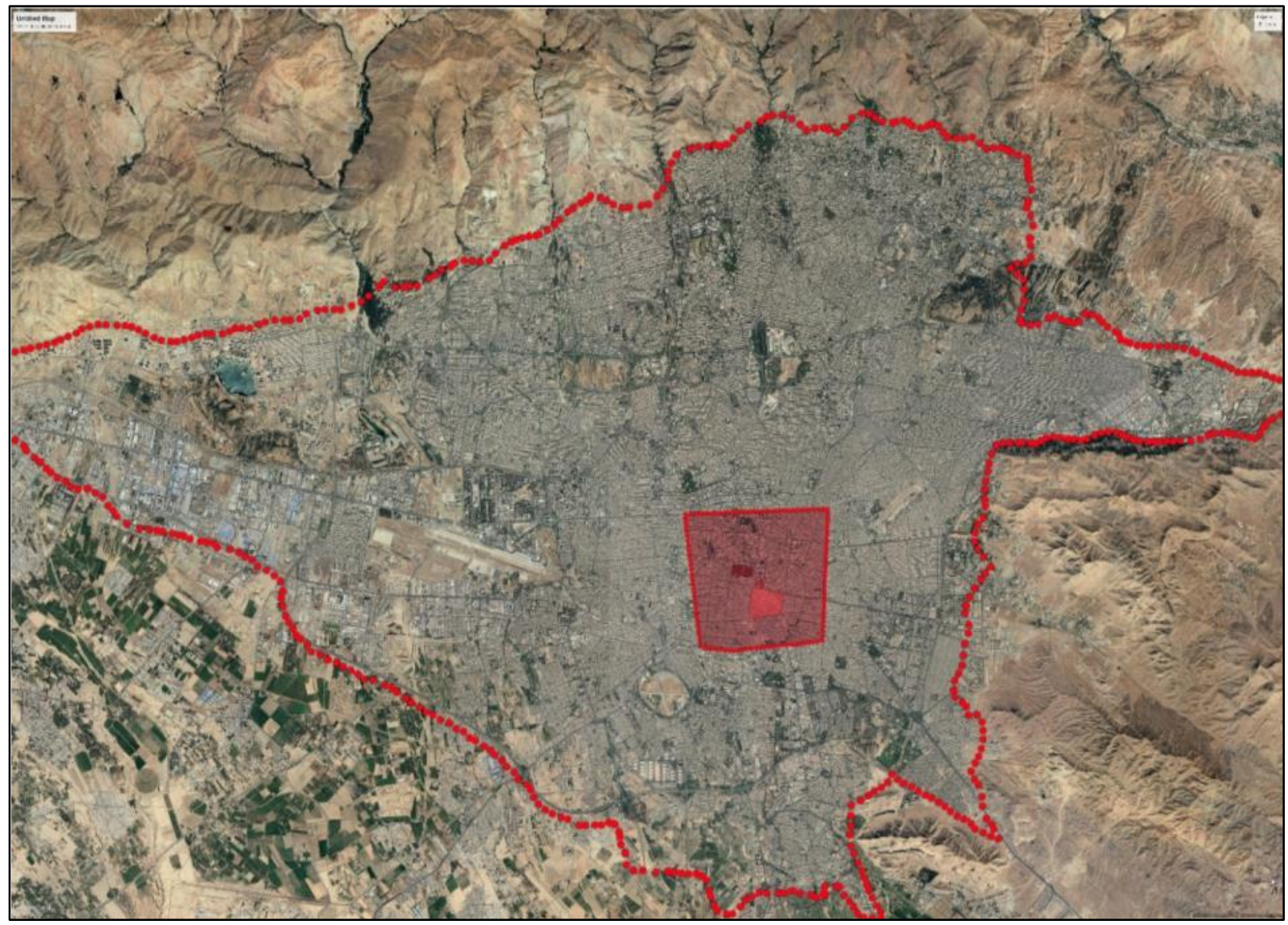




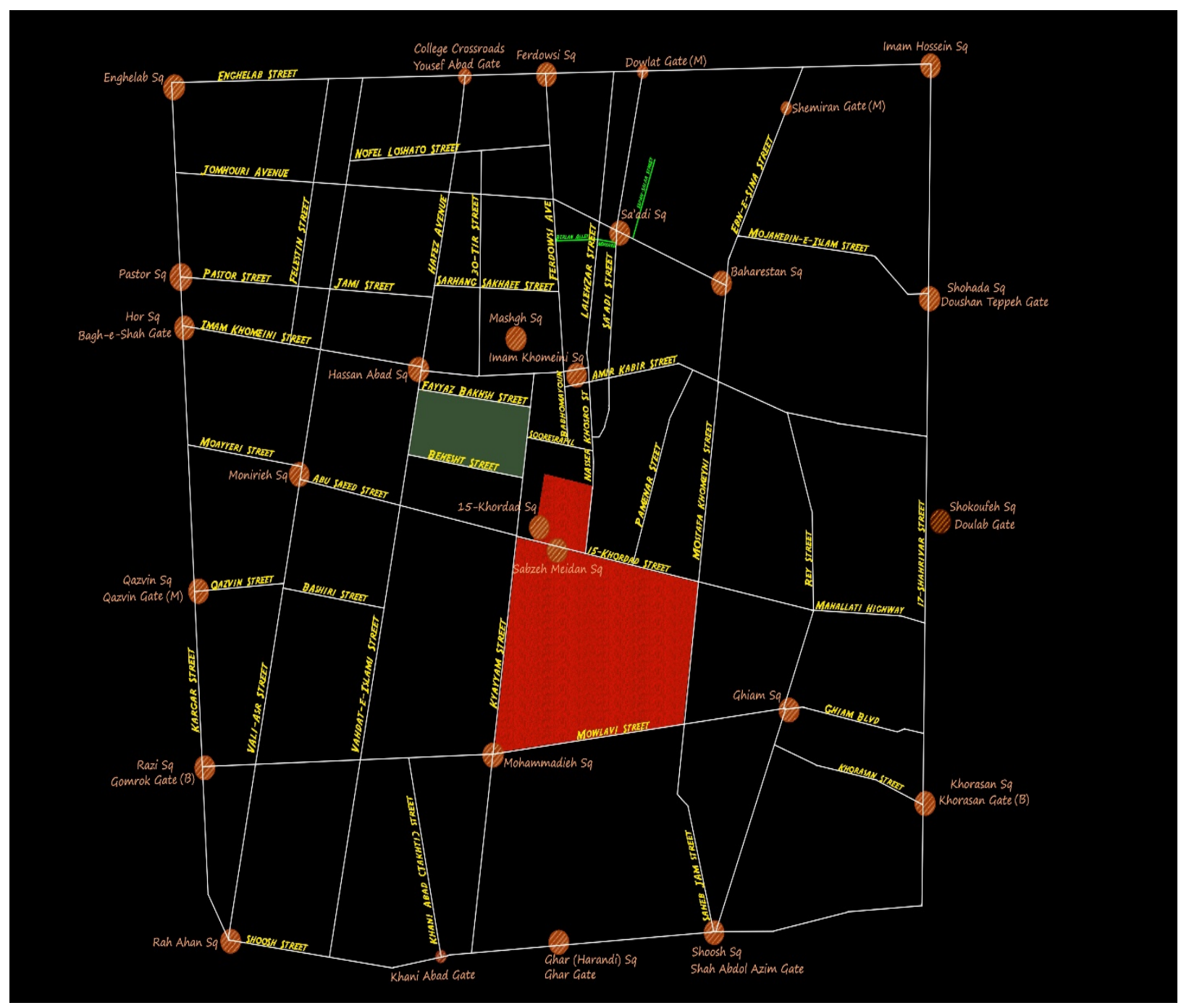

Figure 6. (Top) Location of City Centre in the current Tehran's map (Source of the base map: Ref. [33]; Source of the diagram: Author, 2019); (bottom) The location of 15-Khordad Street, Sepah-Salar Street and Berlan Alley in the City Centre of Tehran (Source of the base map: Ref. [33]; Source of the diagram: Author, 2019)

As Figure 7 presents, the footprints of Nasseri style can be found in the restoration of the pedestrian-based street of 15-Khordad. The two rows of shops, cafés and restaurants, and small-scale shops of fresh juices, and stores of other types junk foods constitute the main attractions of this street for many Tehranians of all around the city. Furthermore, the horse-drawn phaetons, electric cars, and electric train-shaped wagons (tramways) form a combination of traditional and modern attractions for this car-free recreational street. These transport facilities promote the use of clean energy and familiarise all visitors with the globally developing strategies associated with the terms 'car-free' and 'clean' energies [5,34,35].

The whole area of Grand Bazaar and its neighbourhood -in particular the area of 15-Khordad pedestrian pathis located in the congestion area of Tehran and thus the accessibility to the area is mainly by public transport including bus, BRTs (Bus at Rapid Transit), tubes (undergrounds) and line-based ${ }^{6}$ taxis $[3,5,36] .15$-Khordad car-free street is the main connecting axis between the destination (closest) access point of public transports (in Galubandak Crossroads) and Grand Bazaar. The integrated transit system with modern and traditional patterns in this path addresses various groups of users including the visitors with recreational and fun motives, people with large items returning from shopping from Bazaar, and users with disability or tired of walking (in particular in their returns from Bazaar). 

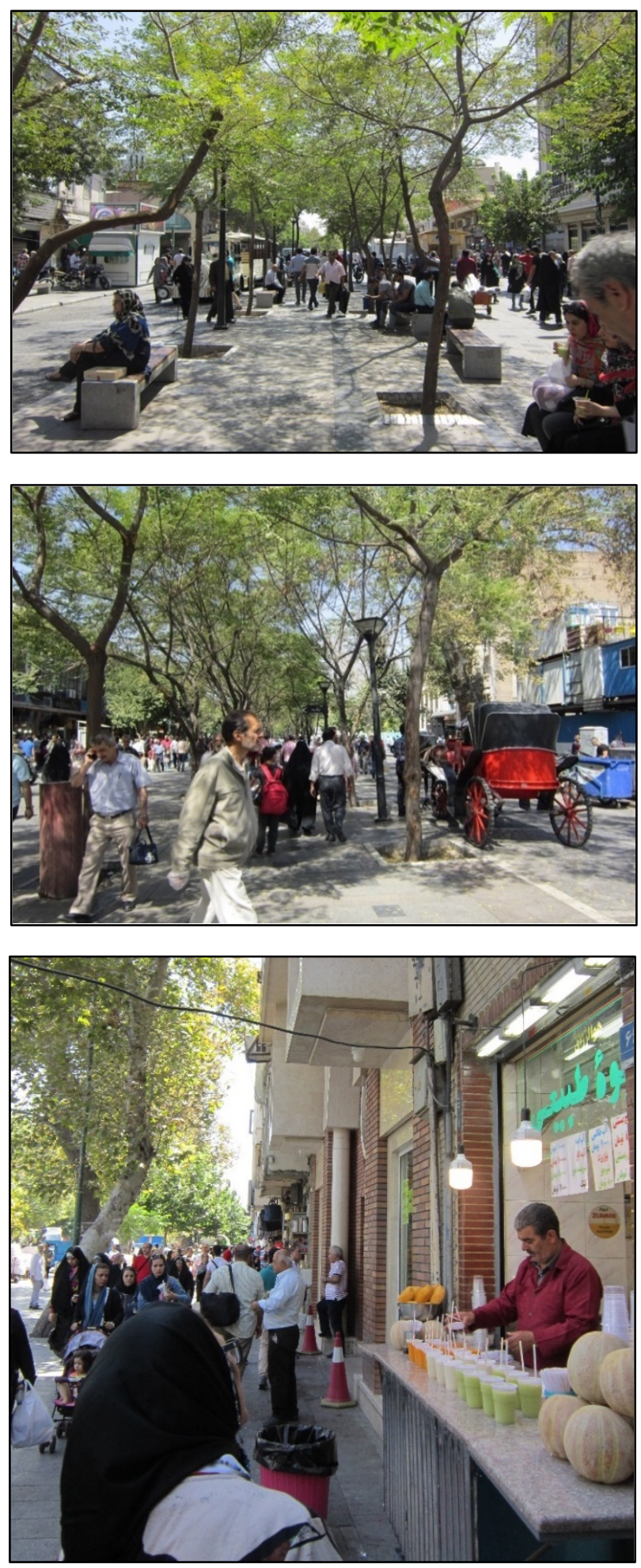

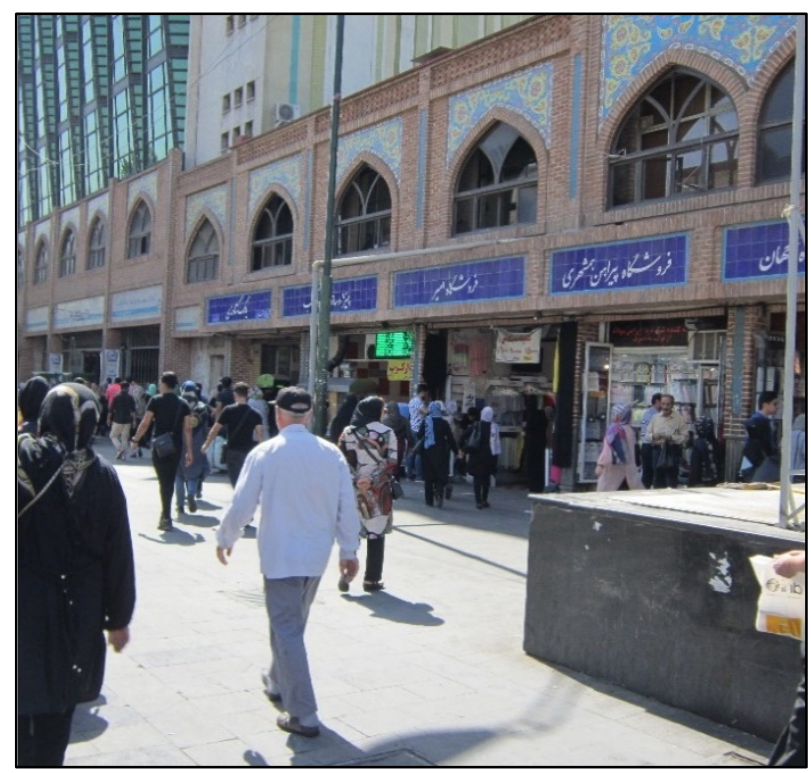

Figure 7. 15-Khordad Street: (top and middle 1 images) Overall view and the tramway for clean transit; (middle 2) overall view and horse-drawn phaeton for clean transit; (bottom) examples of small-scale shops, cafés, and juice shops on both sides (source: Author, 2019)
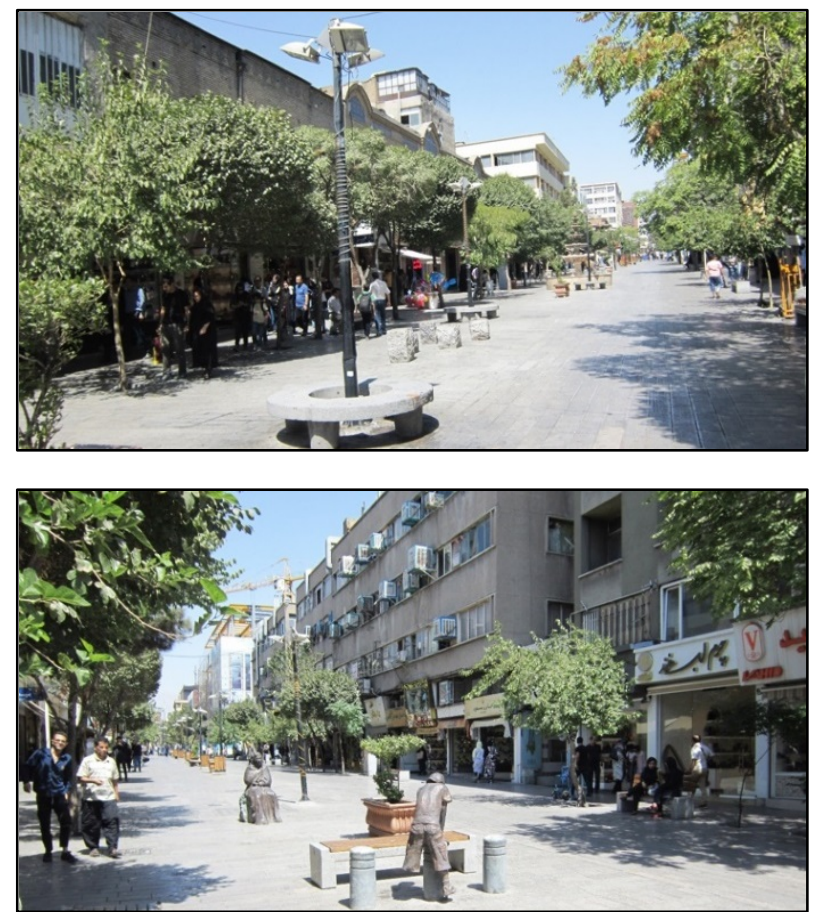

Figure 8. Overall view of Sepah-Salar Street and its shoes-bags stores (Source: Author, 2019) 
Sepah-Salar Street —also known as Sepah-Salar Garden-Street - is a north-to-south pedestrian path located between the two squares in Central Tehran called Baharestan and Sa'adi (please see Figure 6 for the exact location). With a length of $0.5-\mathrm{km}$, this street is a hub for selling shoes and bags in Tehran. Figure 8 depicts an overall view of this street. Remaining from the time of Qajar dynasty (1794-1925) in Iran, this car-free street with rows of shoes-bags boutiques on its both sides has been recognised as the target point of many Tehranians interested in small-scale shopping. It should be noted that many historic buildings related to the time of Qajar dynasty — particularly the buildings associated with signs of cultural eclecticism incorporating traditionalism and modernism - are mainly located in walking distances of this street. For future design and planning strategies, this point would make the possibility of creating a pedestrian-based recreational-historical area $[3,16,23,27,28]$.

Berlan Alley, is an east-to-west pedestrian-based alley located near the embassy of Germany and between the two main axes called Ferdowsi Ave and Sa'adi Street (please see Figure 6 for exact location). Berlan Alley has been recognised as a shopping hub for many Tehranians. Direct observation has revealed that this street includes a wide range of products including occasion wear, bridal dresses and gowns, wedding accessories, loungewear, lingerie and underwear, nightwear and pyjamas, tops and T-shirts, hosiery, shoes, bags and luggage, sunglasses, cosmetics and toiletries, fabrics, accessories and jewellery.

As shown in Figure 9, Berlan Alley with roofed, semi-roofed and open segments is also recognised as the entrance of many different shopping passages (arcades) situated on its both sides. Furthermore, this street has been a selling platform of several street vendors. As a result of the low-to-high price opportunities and the diverse spectrum of products alongside and in the neighbourhood of Berlan Alley, this 1.2-km alley attracts different groups of users from all around Tehran. This has thus resulted in presence of crowds of Tehranians in this area since its infancy and more specifically in the last 50 years [5].
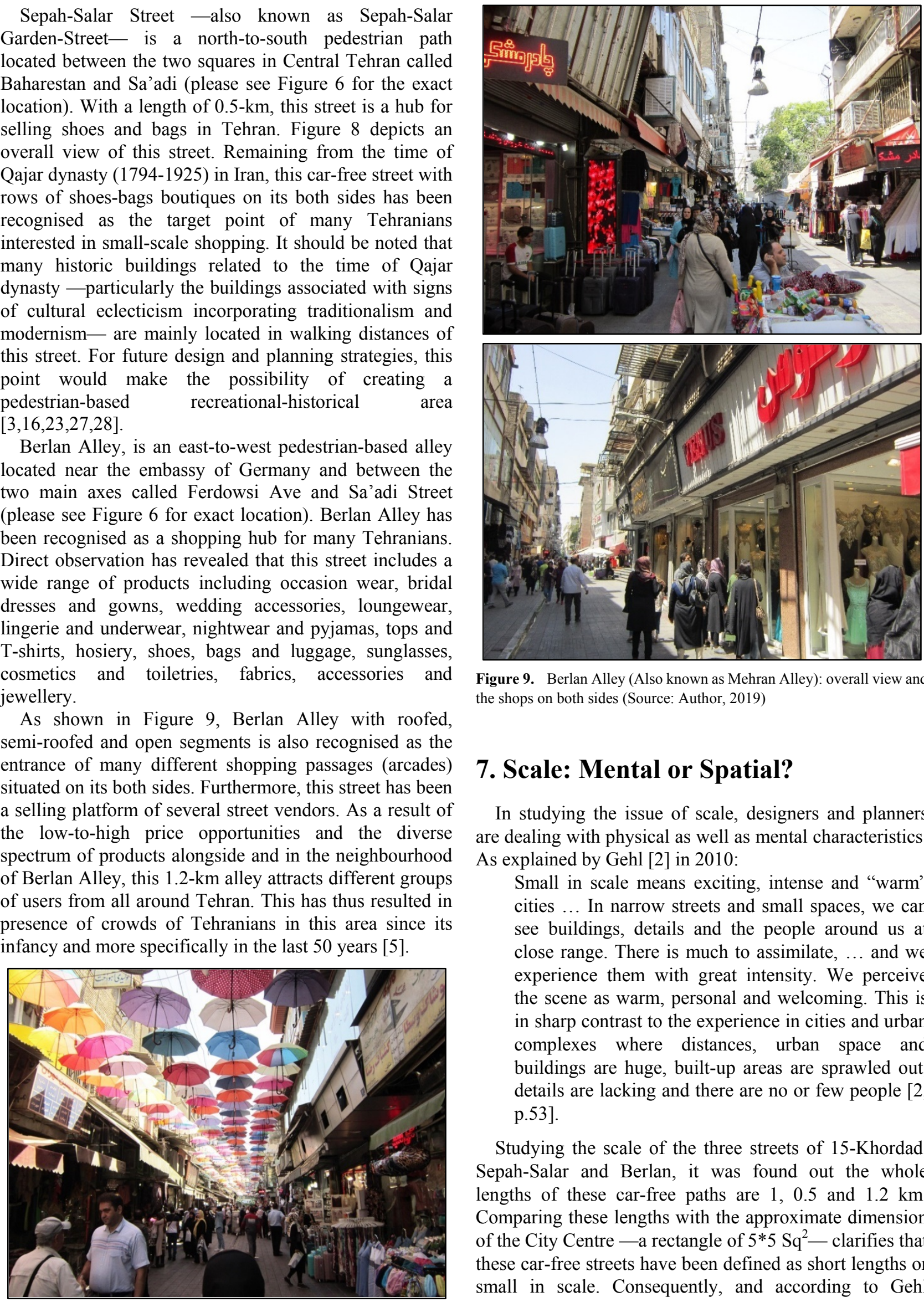

Figure 9. Berlan Alley (Also known as Mehran Alley): overall view and the shops on both sides (Source: Author, 2019)

\section{Scale: Mental or Spatial?}

In studying the issue of scale, designers and planners are dealing with physical as well as mental characteristics. As explained by Gehl [2] in 2010:

Small in scale means exciting, intense and "warm" cities ... In narrow streets and small spaces, we can see buildings, details and the people around us at close range. There is much to assimilate, ... and we experience them with great intensity. We perceive the scene as warm, personal and welcoming. This is in sharp contrast to the experience in cities and urban complexes where distances, urban space and buildings are huge, built-up areas are sprawled out, details are lacking and there are no or few people $[2$, p.53].

Studying the scale of the three streets of 15-Khordad, Sepah-Salar and Berlan, it was found out the whole lengths of these car-free paths are $1,0.5$ and $1.2 \mathrm{~km}$. Comparing these lengths with the approximate dimension of the City Centre - a rectangle of $5 * 5 \mathrm{Sq}^{2}$ - clarifies that these car-free streets have been defined as short lengths or small in scale. Consequently, and according to Gehl 
(2010), these streets can be perceived with the feelings of warm and welcoming. This would thus invite various groups of Tehranians from all around the city everyday $[2,3,5,33]$.

In other words, on one hand the spatial dimensions of these pedestrianised streets represent small scale. On the other hand, their warm and friendly atmosphere as well as their variety of products and recreational characteristics (particularly in 15-Khordad Street and Berlan Alley) respond to Tehranians in the big scale of the city. This has resulted in the presence of crowds of Tehranians in different parts of the City Centre. The following images in Figure 10 best represent the overcrowded-ness of these three streets which is the outcome of the responsive radius of these streets as the city scale.
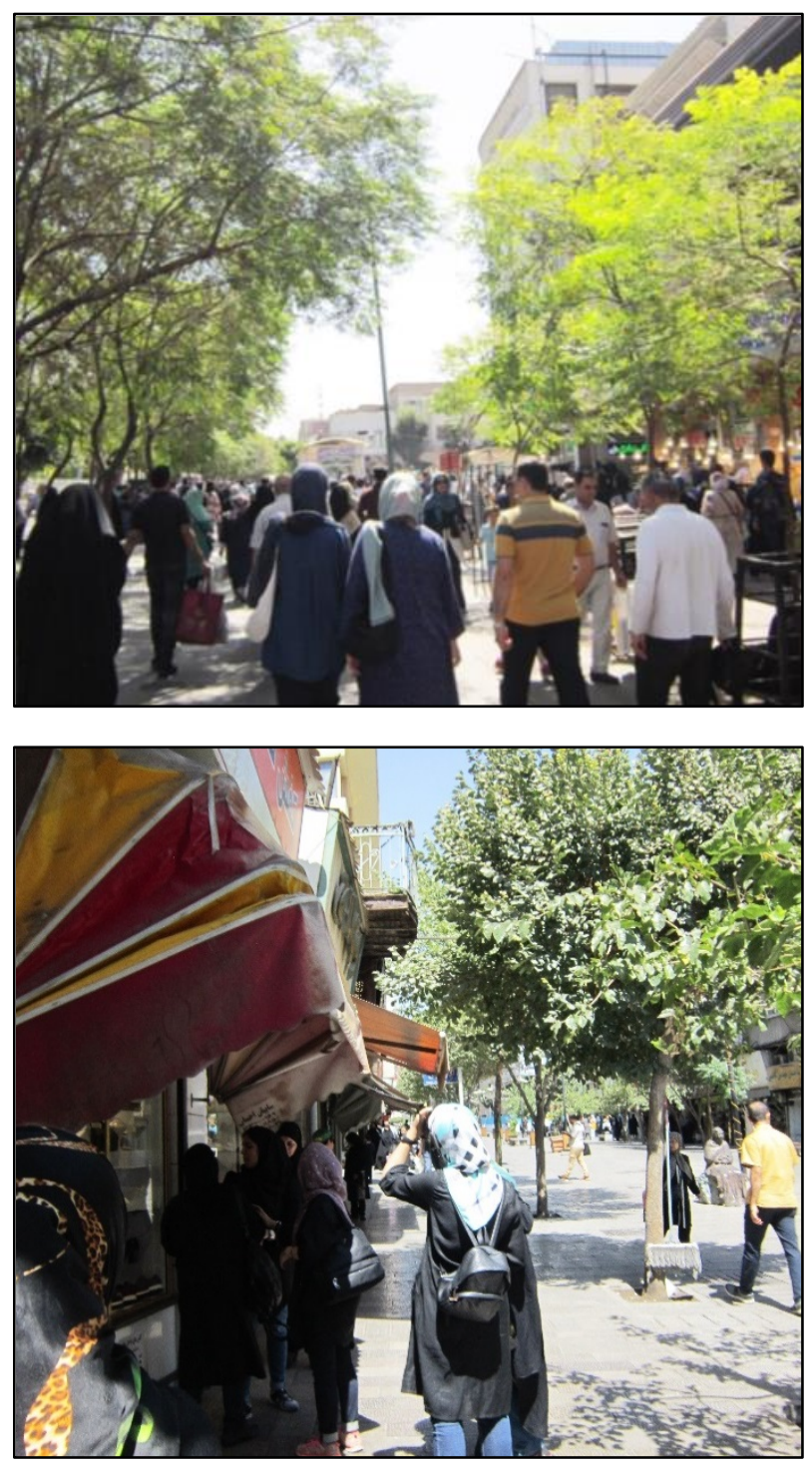

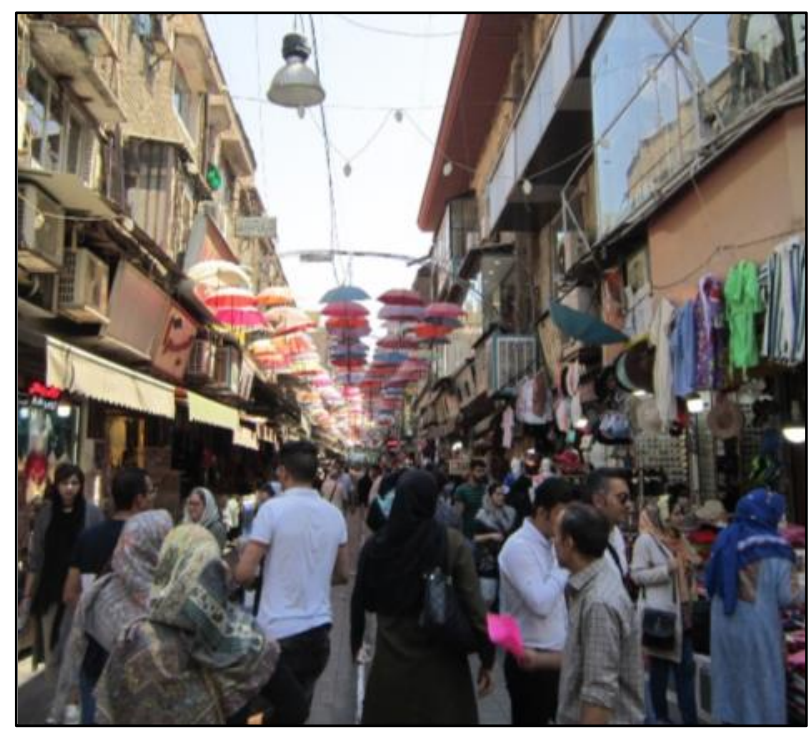

Figure 10. Responsive radius of case study streets as city-scale: (top) 15-Khordad Street, (bottom-left) Sepah-Salar Street; (bottom-right) Berlan Alley (Source: Author, 2019)

\section{Age-Gender Groups}

As already explained, a combination of photo-taking and dot-based analysis of the different groups has been applied. In considering the two indicators of age and gender of users of these three case study streets, six categories have been identified. This mainly includes: 1) woman; 2) man; 3) child, 4) woman in car/on motor; 5) man in car/on motor; 6) child in car/on motor; and 7) car/motor. A single image (Figure 11) is exemplified here to further clarify how the qualitative and quantitative process of analysis has been evolved. This process has been implemented on all captured images throughout the whole lengths of the three case study streets. The findings have been inserted to Excel in order to provide the possibility of identification and comparison between the age-gender groups individually and collectively.

As explained by Gehl and Svarre [1] in 2013, public life incorporates a wide range of activities and contexts and thus can be "understood in the broadest sense as everything that takes place between buildings, to and from school, on balconies, seated, standing, walking, biking, etc. It is everything we can go out and observe happening ... it is the complex and versatile life that unfolds in public space" [1, p.2]. In this research, direct observation of public life - that is complemented by photography and dot-based analysis (with counting) - particularly in the three case study streets elucidates the major and minor groups of users, preferences and dislikes, and latent potentials and problems. This analysis needs to be reflected in the design and planning of streets of City Centre while defining strategies to achieve inclusiveness. 

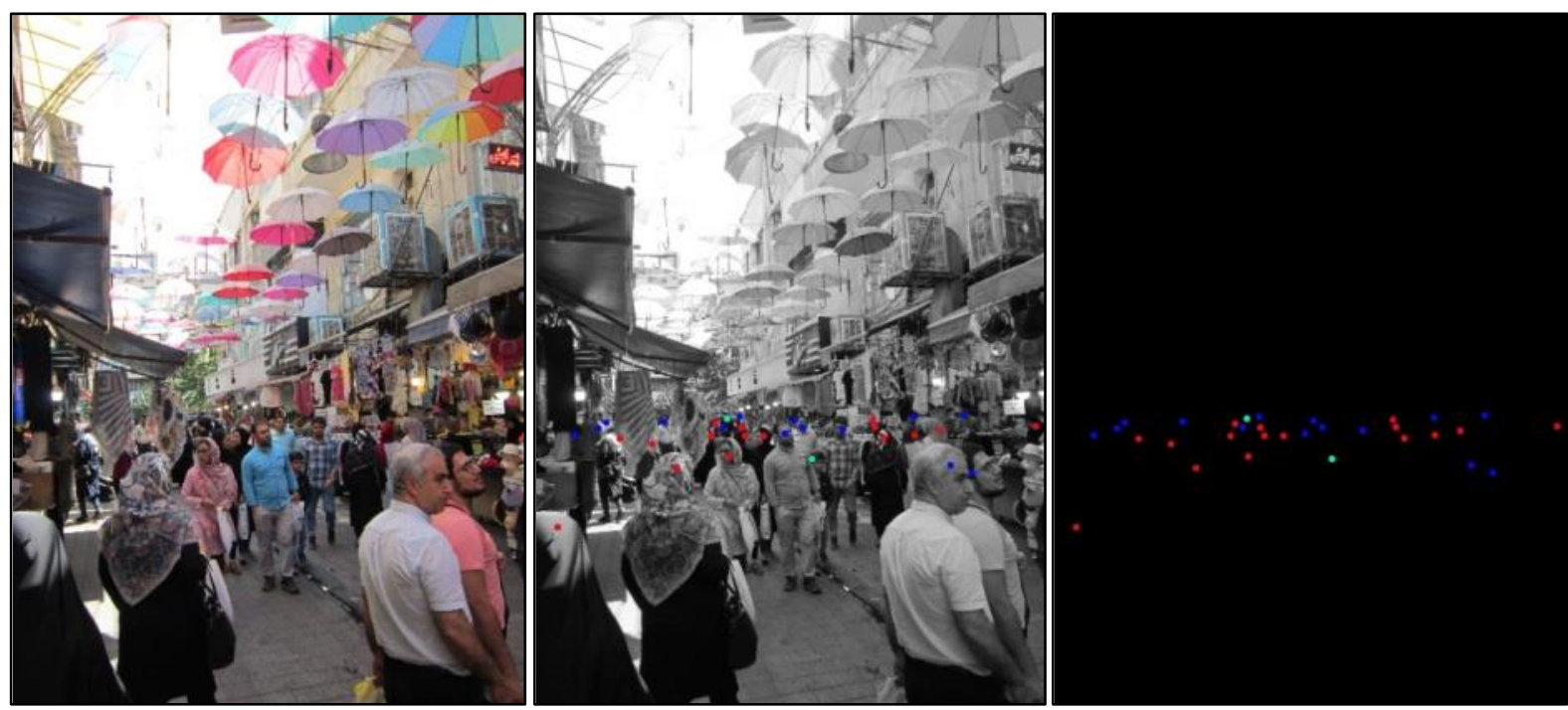

Figure 11. The process of dot-based analysis - Example (red: women; blue: men, cyan: children; hatched red: women in vehicles; hatched blue: men in vehicles; hatched cyan: children in vehicles; green: vehicles7) (Source: Author, 2019-2020

Counting as a research method or technique has been applied in many researches associated to public life so far. "Counting is basic to public life studies. In principle, everything can be counted: number of people, gender division, how many people are talking to each other ... Counting provides quantitative data that can be used to qualify projects and as arguments in making decisions" $[1$, p.25]. In counting, however, certain degree of imprecision is inevitable. As further discussed by Gehl and Svarre [1], "the general question of gender and age can be registered by observation, naturally allowing for a certain degree of inaccuracy in making a subjective evaluation of age group" [1, p.14].

As shown in the diagram below in Figure 12, in 15-Khordad Street, the first major group of users is men and the second group includes the women. In this street, children and young adults have not been recognised as key users. In other words, the majority of users of this street are adults, including men and women and thus it is not mainly used by young adults as groups or by children and young adults accompanying their parents. With a comparison of the ratio of men and women, however, it becomes clear that on average, men are significantly more.

The reason is that the whole area of Grand Bazaar, 15-Khordad and their neighbourhood has always been acknowledged as the beating heart and focal point of business market of the whole country since Tehran's infancy as the capital. As a result, the dominant group of present people in this district are the male ancestral shop-owners and businessmen. In the recent two decades, however - particularly since the decade of confrontation (1999-2009) (noted by Fathi [37]) and onwards - women have significantly (re)gained their roles in public sphere through various economic and social activities with an accelerating speed. A key reason of this acceleration is the unification of different groups of women in foregrounding their rights in public life $[3,16,37,38]$.

Direct observation has shown that, at present, the whole area of Grand Bazaar and 15-Khordad Street represents a composition of trading and recreation. In other words, in addition to large-scale commerce and national-international wholesale, this area has been substantially recognised as a target point of shopping for adults, particularly for groups of women during the days, in the time that children are at school. This has led to creation of a recreational as well as business destination point for many Tehranians through a daily basis.

It should be noted that the recreational facilities in 15-Khordad Street, such as electric cars or tramways, horse-drawn phaetons, cafés, traditional restaurants and vendors of junk foods have started to increase the attractiveness of this car-free street for younger generations. In other words, a comparative investigation through direct appraisal in September and December 2019 has clearly portrayed the augmentation of the presence of younger generations in this pedestrianised street. 

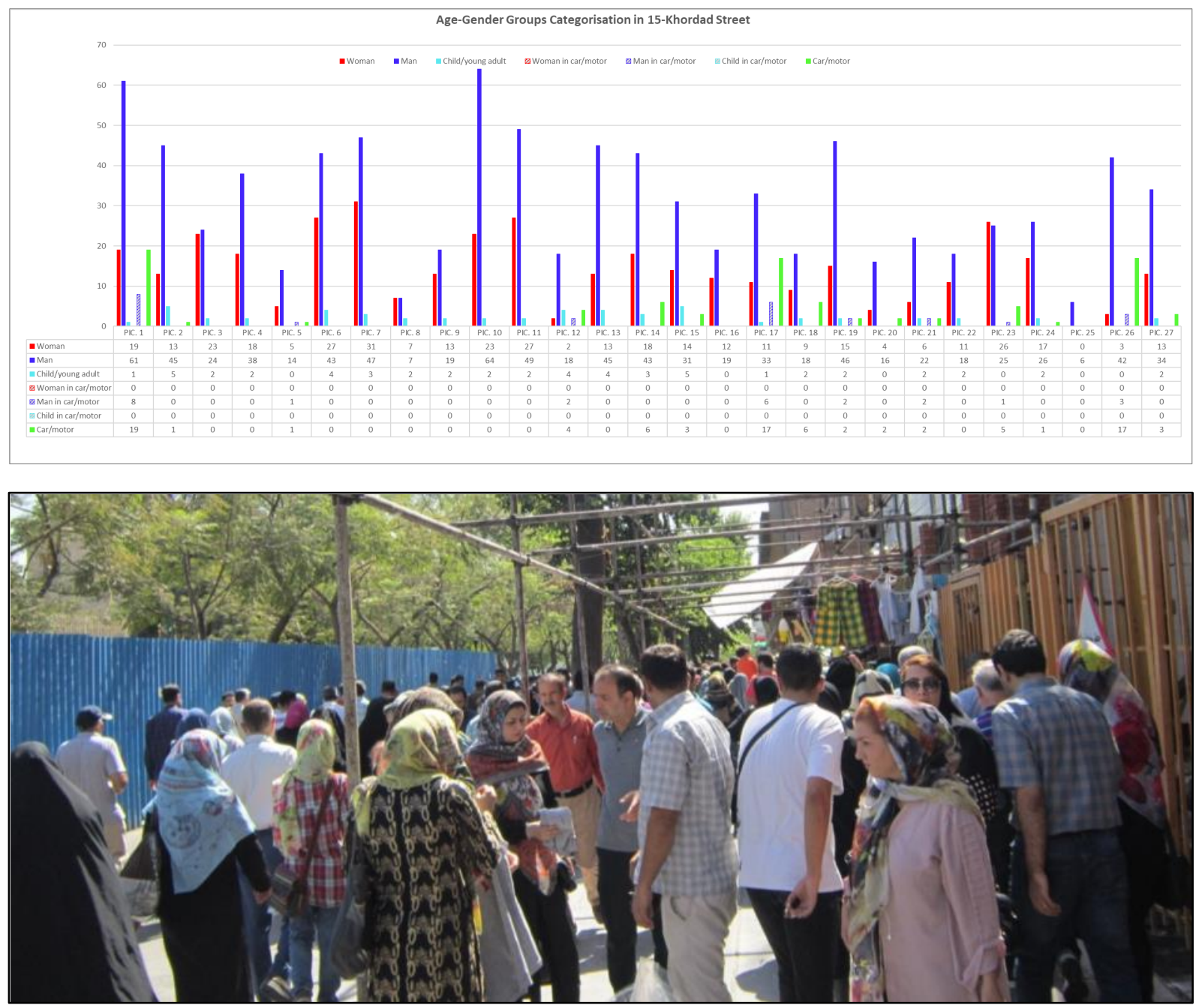

Figure 12. (Top) Classification of users and their ratios based on the indicators of age and gender (source: Author, 2019-2020); (bottom) adults as the main users (major groups) of 15-Khordad Street

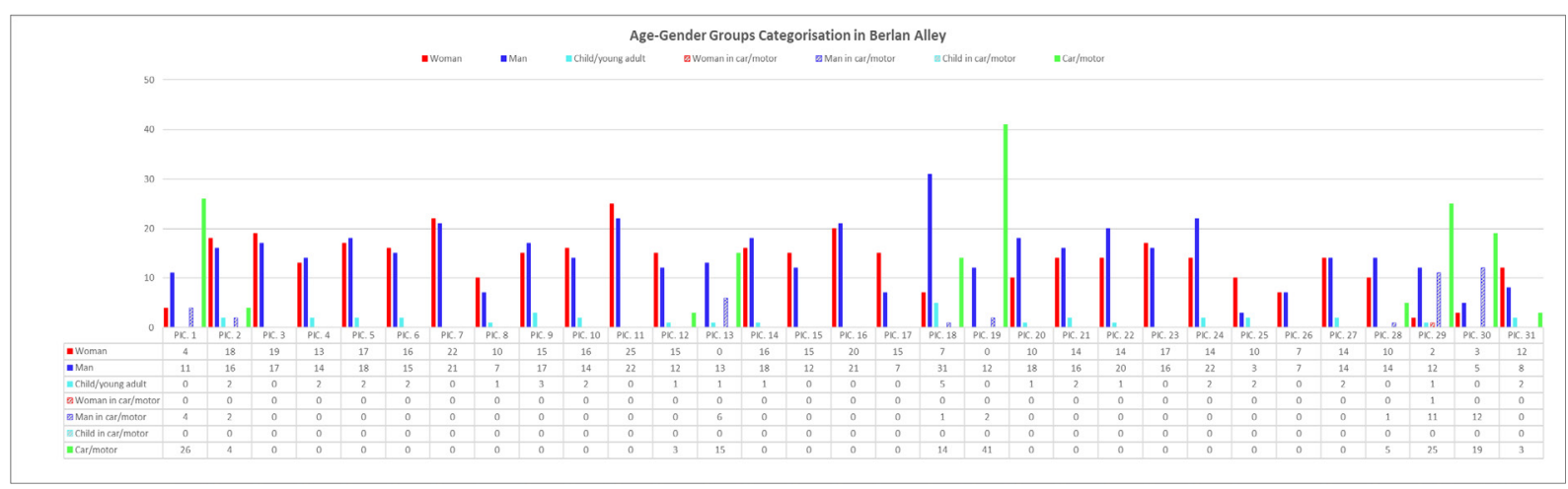



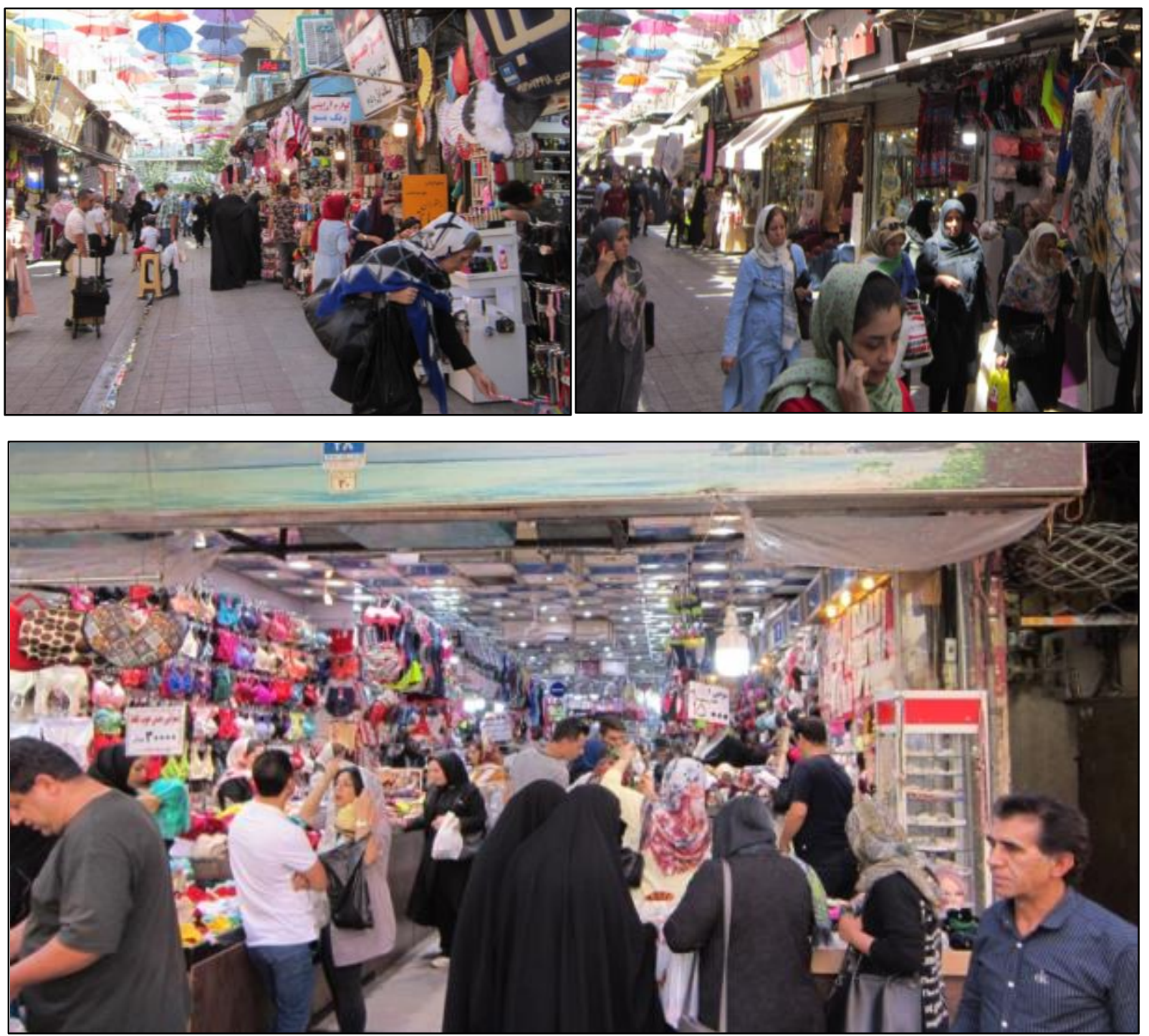

Figure 13. (Top) Classification of users and their ratios based on the indicators of age and gender in Berlan Alley (source: Author, 2019-2020); (middle) presence of women as visitors in Berlan Alley (Source: Author, 2019); (bottom) presence of women as active members of shopkeepers or shop assistants in Berlan Alley (Source: Author, 2019)

As shown in Figure 13, similar to 15-Khordad Street, Berlan Alley is primarily used by adults, including men as the first main group and women as the second group of users. Consequently, this shopping-recreationalpedestrian street is not mainly recognised as a favourite target point for children and young adults. In comparison to 15-Khordad Street, however, the difference of ratios between the two main groups of men and women is less in Berlan Alley. Similar to 15-Khordad Street, the direct appraisal has revealed the presence of women as active members of shopkeepers (or shop assistants) as well as the visitors (shoppers).

In comparison to the two previous streets, Sepah-Salar
Street is used by adults as well as by young adults and children. As Figure 14 illustrates, in a hierarchical order in this street, the users mainly include men, women and children/young adults. In other words, this street is recognised as a hub for all family members with a range of ages to come to the area with the purpose of buying shoes and bags. One main reason of the presence of more children and young adult might be the less numbers of shops. In other words, the density of the shops is less in Sepah-Salar Street in comparison to 15 -Khordad Street and Berlan Alley. The reason of the difference of the presence of young children and adults in these three streets is further discussed in the following section. 


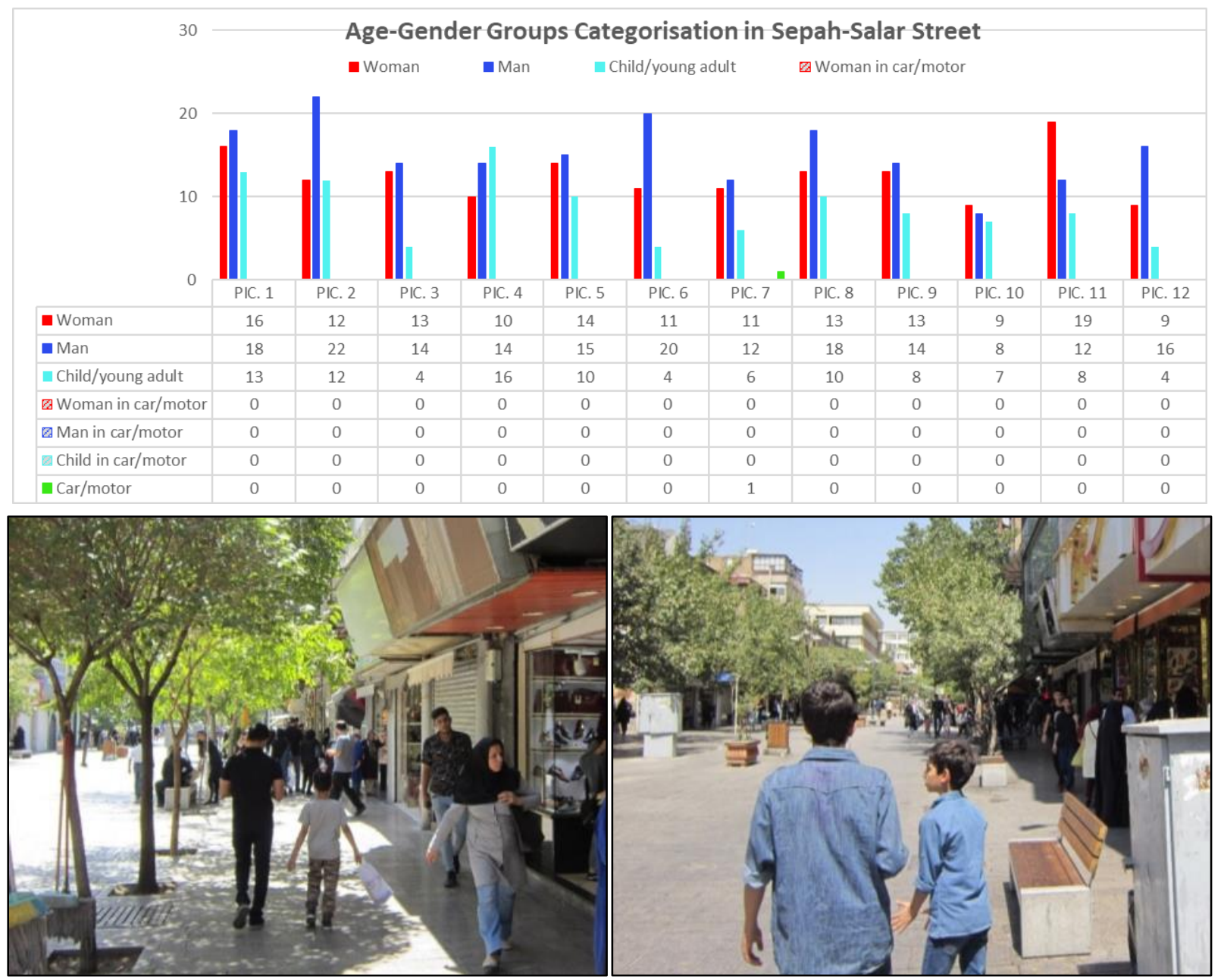

Figure 14. (Top) Classification of users and their ratios based on the indicators of age and gender in Sepah-Salar Street (Source: Author, 2019-2020; (middle and bottom images) presence of children and young adults in Sepah-Salar Street (Source: Author, 2019)

\section{Further Analysis about the Presence of Children and Young Adults}

In investigating the public sphere and urban spaces, understanding the diversity is quite necessary. Considering the various groups of age and gender and special circumstances such as elderly people, ethnic minorities, and poor is crucial to achieve inclusiveness in design and planning. As further explained by Madanipour [39] in 2010:

In spatial terms, public spaces are by definition public, and as such expected to be accessible to all. However, public is not a single entity, as it is composed of different social strata, each with a different set of characteristics, interests and powers. Furthermore, within those strata there are a large number of individual differences [39, p.9].

In investigating the factor of public-ness, it is necessary to study physical aspects such as accessibility and mobility, as well as the mental and spiritual features such as and the feelings of interest and attractiveness. In other words, a spectrum of physical, mental and spiritual expectations needs to be fulfilled for various groups of users to achieve inclusiveness in the public spaces in the City Centre of Tehran. Considering the factor of age, in particular, the group of children and young adults needs to be taken into foreground as they have been gradually neglected in the past decades in the planning system of this metropolis. In the area of Grand Bazaar, 15-Khordad Street and their neighbourhood, the needs and desires of this group have been disregarded and this has made the Grand Bazaar district and its neighbourhood a less-interesting destination point for children and young adults.

A similar trend of 15-Khordad Street is taking place in Berlan Alley. Considering 15-Khordad Street and Berlan Alley, it can be concluded that while the number of boutiques becomes more, the number of men and women will be more as active members of shopkeepers. In other words, there would be more men and women who are present in the area working in the business and trading. In this sequence, more shops invite more people to come for shopping or using recreational facilities such as traditional cafés and restaurants. In this consecutive scenario, however, overcrowded-ness results in the less feeling of 
safety for children and young adults and make the area more interesting for adults [5]. Little presence of children and simultaneously the overcrowded-ness are shown in the following images (Figure 15).
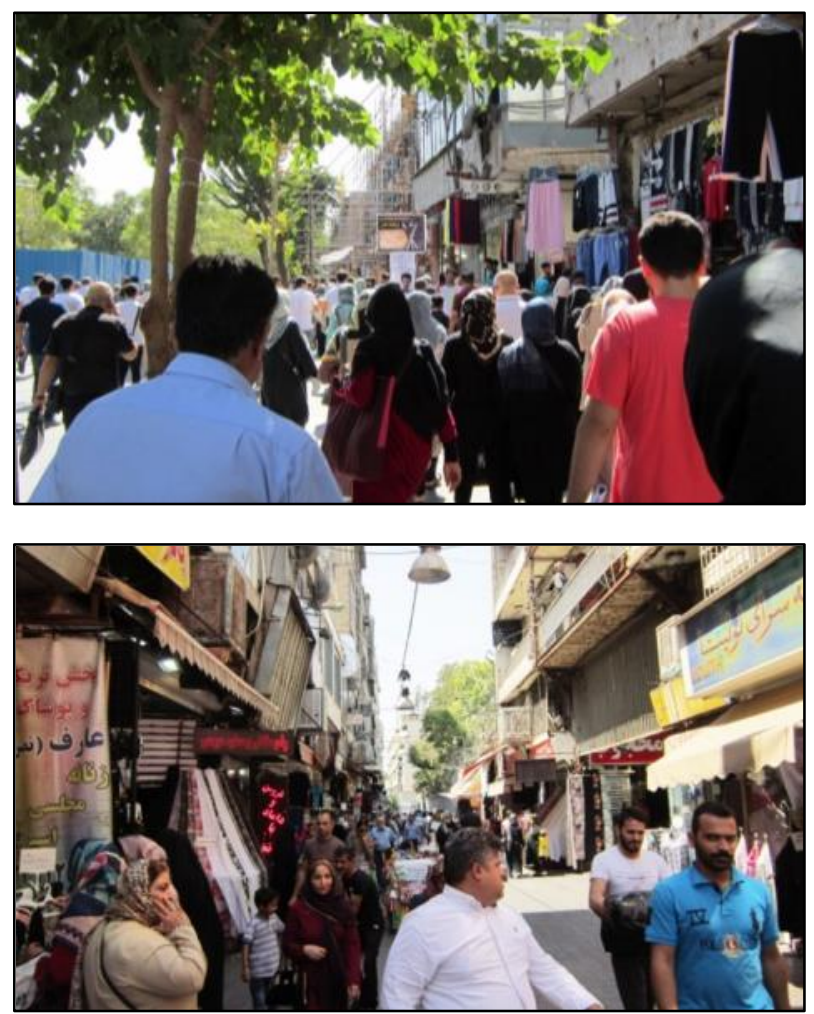

Figure 15. Overcrowded-ness and the subsequence of little presence of children and young adults: (Top) 15-Khordad Street; (bottom) Berlan Alley (Source: Author, 2019)

In short, as a result of overcrowded-ness, mobility within the area of these two streets has turned to a difficulty, or more precisely a challenge, particularly for vulnerable groups including children and young adults as well as the elderly people and users with disability. Furthermore, as a result of overcrowded-ness, the safety of this area has significantly decreased, and this mainly addresses the groups with stronger need of protection and care such as children [5]. In addition to the discussed spatial issues including the overcrowded-ness, mobility and feeling of safety, one other factor that has resulted in the little presence of children and young adults is related to motives and reasons for coming to the area.

At present, these two streets are merely associated with different-scale shopping and thus the other stimulations such as leisure, enthusiasm, and entertainment have been faded. As a result, groups with less interest in shopping, such as children and young adults, haven't created strong connectivity and thus formed a minor presence in the area.
It should, however, been noted that, recently, specific recreational facilities with the use of clean energies in 15-Khordad Street have started to create interest for younger generations. For instance, following a combination of modern and traditional patterns, this street depicts horse-drawn phaetons as well as electric cars and trams for short-distance transits. Figure 16 further clarifies this point.
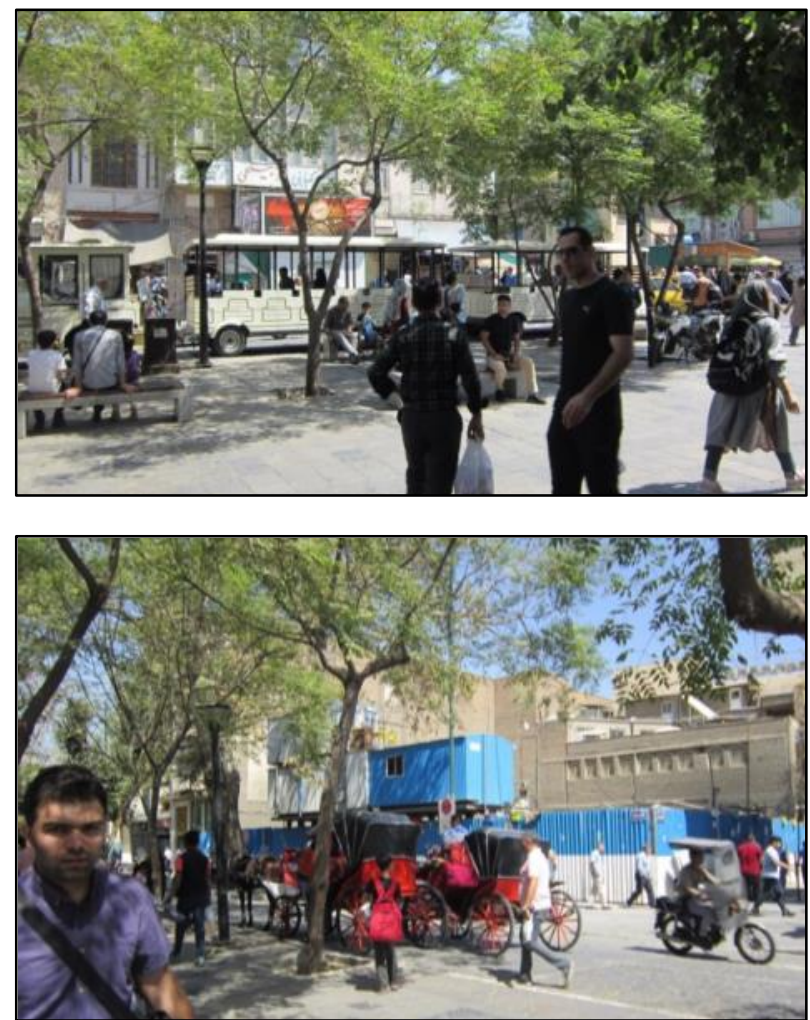

Figure 16. Co-presence of modern and traditional facilities of clean movements in 15-Khordad Street as growing interesting facilities for children and young adults (Source: Author, 2019)
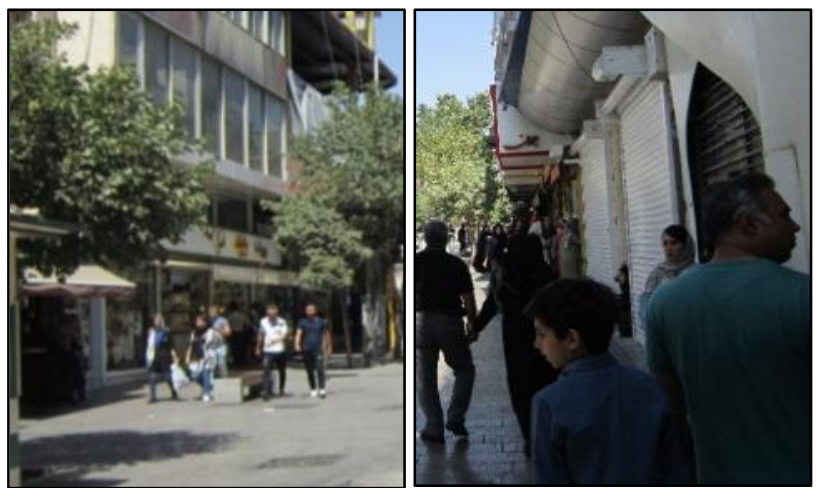


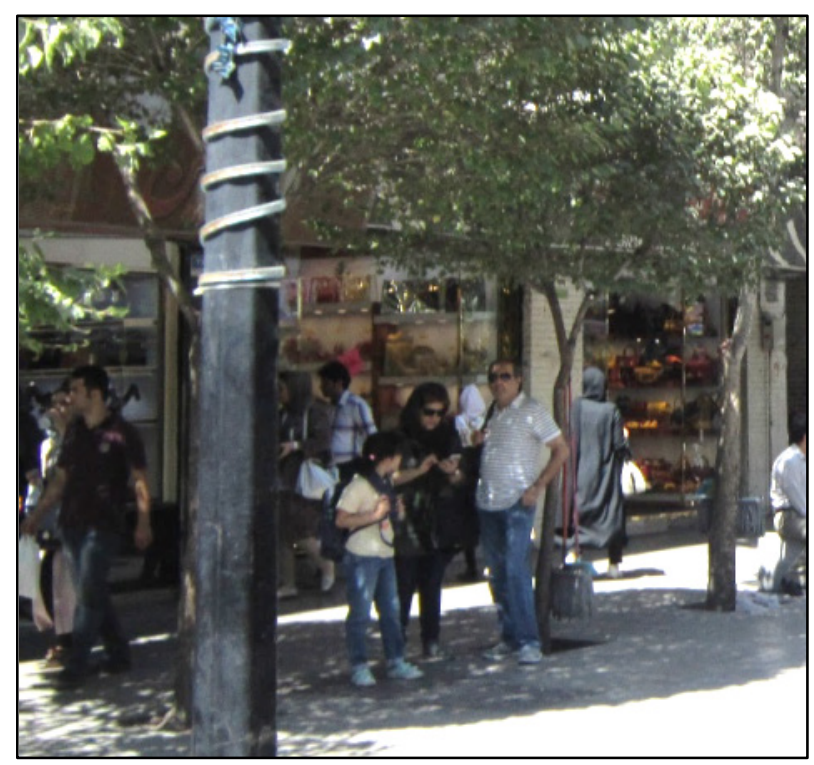

Figure 17. Presence of young adults and children in Berlan Alley (Source: Author, 2019)

As direct observation revealed, in contrast to 15-Khordad Street and Berlan Alley, Sepah-Salar street attracts younger generations more significantly. Less density of boutiques on the two sides of this $0.5-\mathrm{km}$ pedestrianised path and subsequently the less overcrowded-ness, and thus easier mobility and more feeling of safety have made this street interesting for children and young adults. As a result, in comparison to 15-Khordad Street and Berlan Alley, this street is mainly based on family uses. As shown in Figure 17, this hub for purchasing bags and shoes consists of a variety in products for children and young adults. However, the two other case study streets mainly present products for adults in single sale (retail trade) as well as wholesale [5,33].

The following diagram (Figure 18) provides an overall comparison between these three streets about age-gender groups particularly a comparison of the portions of younger generations in these three streets. It should be noted that although the scale of all these three streets is urban and thus, they attract Tehranians of all around the city; the number of users of these three streets varies. In other words, the number of visitors of these three streets is quite different despite following an urban scale. Considering the average of each group in three case studies in Figure 18 best clarifies the point.

The comparison of the average and accumulation of the average of the counted numbers of men, women and, children and young adults in 15 Khordad street, Berlan
Alley, Sepah-Salar Street in the diagram below elucidates that, on average, 15 Khordad street is the most overcrowded street between the case studies. The reason is mainly its particular location as this street is situated in the neighbourhood of Grand Bazaar. This street is thus recognised as a transit path to access the beating heart of trading centre of the country, Grand Bazaar.

\section{Pedestrians and Vehicles}

The simultaneous presence of human beings and automobiles has resulted in spread of two different scales in current cities worldwide. Usual buses, BRTs (buses at rapid transit), undergrounds, highways, private and line-based6 taxis, and private cars on one hand, and the pedestrians and cyclists, on the other hand, define two "seemingly" warring premises of scale for urban contexts particularly for the City Centres. With an integrated management, planning and design, however, this challenge might lead to generating potential with varieties of access possibilities in the city and in City Centre.

A variety as well as the integration in City Centre -in uses/functions as well as in access possibilities - can lead to creation of a sustainable City Centre. As further explained by Paumier [4] in 2004, this would be centred on two characteristics including:

- A diverse market. A city's unique character is defined by the diversity and concentration of contemporary uses. These uses generate pedestrian activity and a lively social environment that, in turn, sustain the mix of uses.

- A high-quality place. A visually appealing, comfortable, and secure physical environment will create confidence, commitment, and investment in the community over the long term [40, p.4].

For decades, and as a result of the accelerating presence of cars in an urban context, the human scale has been neglected and disregarded. This has thus necessitated a revival of the human scale to achieve a lively, convivial, safe, healthy, inclusive, and sustainable city [2]. The re-integration of human scale with the design and planning of cities would thus recreate a balance in the spectrum of scales. The three case study streets of this research have been located in the congestion area of Tehran and thus have limited access possibility via private transport. As a result, the main access to these pedestrian-based streets is public transport including bus, BRT, line-based taxis, and general taxis. 

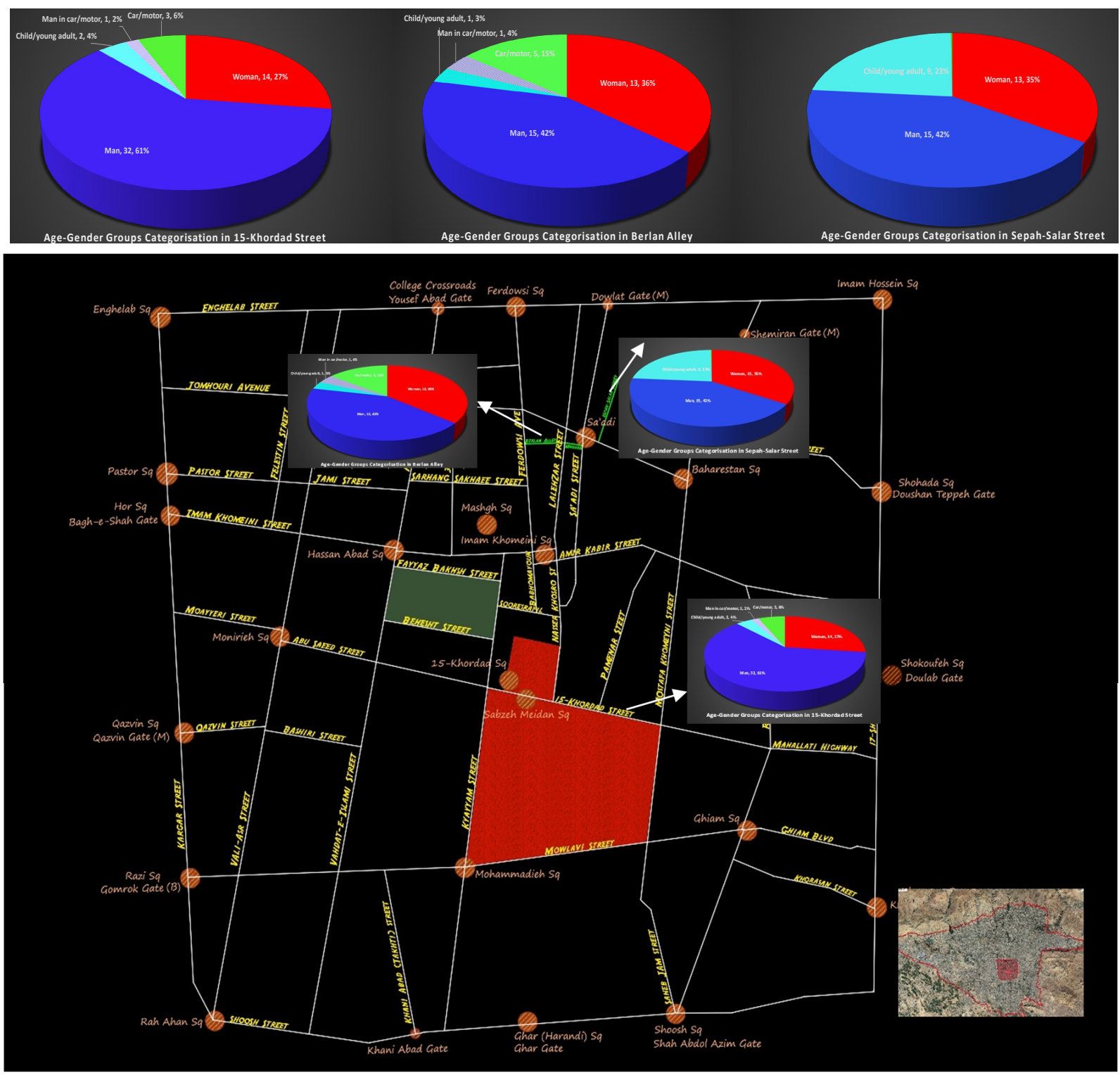

Figure 18. Comparison of the ratios in age-gender classifications in three case study of 15-Khordad Street, Berlan Alley, and Sepah-Salar Street) (Source of the base map: Ref. [33]; Source of the diagrams: Author, 2019-2020)

As a result, a mixture of public transport to access the three streets, and pedestrianisation of these three streets can potentially lead to move towards sustainability in movements and accessibility in City Centre of Tehran. This, however, needs to be studied in detail from two aspects including: 1) the final point of public transport and the entrance of these areas (accessibility); and 2) the meaning of car-free: absolute prohibition or limited entrance of vehicles (mobility) to these streets. 


\subsection{Accessibility and Mobility in 15-Khordad Street}

The main entrance - which is the destination of public transports to this street- is called Galubandak Chaharrah (Galubandak Crossroads). As shown in Figure 19, the lack of a proper organisation of movements in Galubandak Crossroads between pedestrians, motorcyclists, buses and taxis have created interferences of pedestrians and vehicles. In other words, this entrance point is a chaotic mixture of pedestrians and different-scale vehicles. This shows a chaos in movements in the entrance which makes the image of the whole area of 15-Khordad Street less comfortable for pedestrians. As a result, in order to facilitate the movement for pedestrians, a proper management between the existing different-scale access transport in the destination point is crucial. The following images of interferences in Galubandak Crossroads further clarify the point.

In order to study the second above-mentioned characteristic - the meaning of car-free in this streetthe images of this street, have been applied for the analysis. In this process, three categories have been identified. This includes the pedestrians, cars and motorcycles, and people in vehicles (in cars or on motors). Similar to the analysis of section 5 of this paper, the photos and the existing three groups have been graphically converted into a dot-based system, by counting the number of each group in all images and inserting the quantities to the software of Excel. In the final step, the comparative quantities are used to analyse the overall number of vehicles and pedestrians through the following diagrams (Figures 20 and 21).

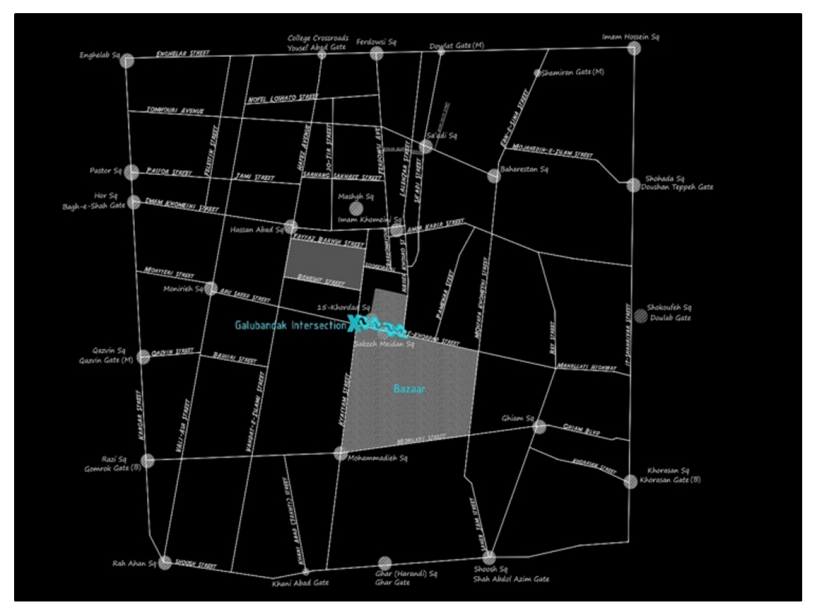

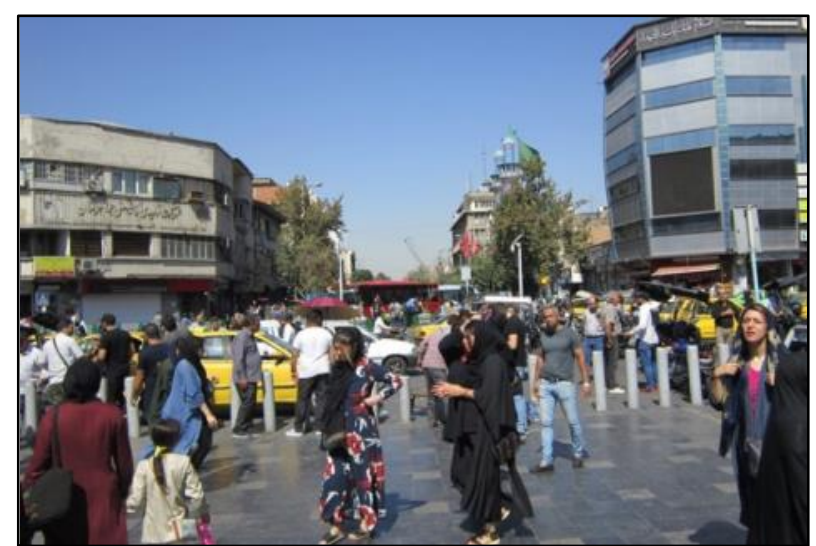
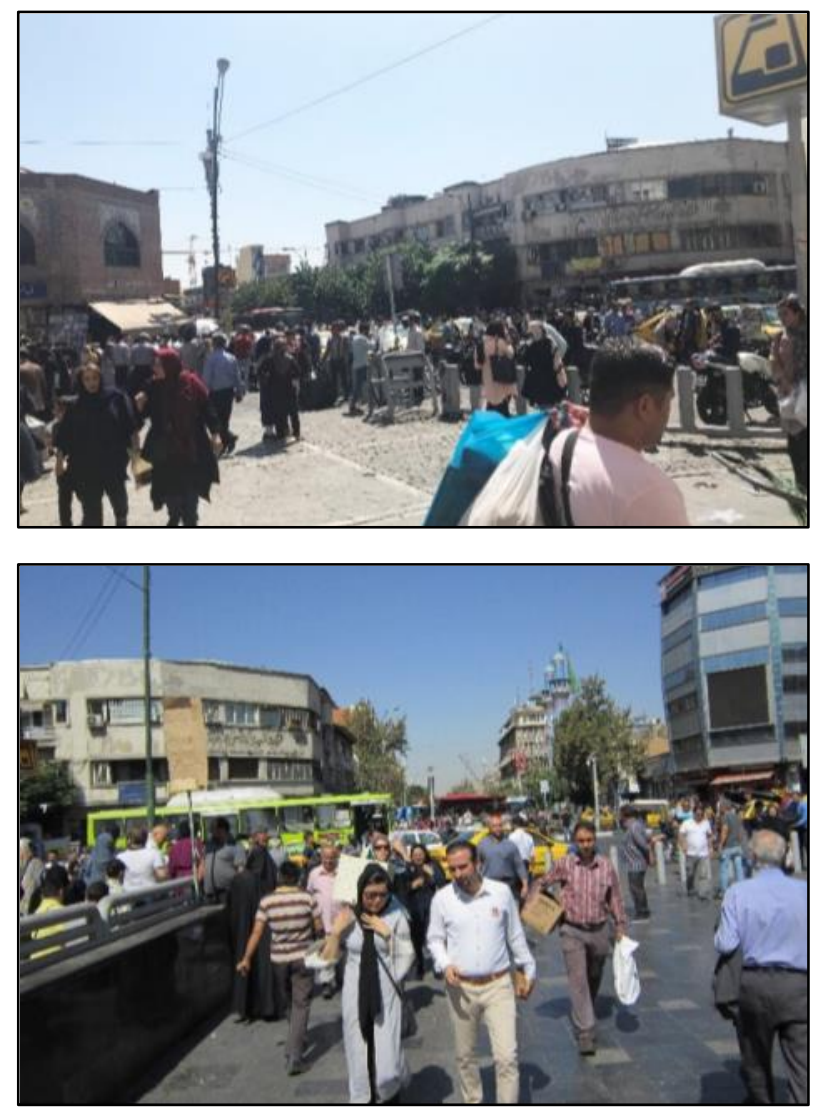

Figure 19. The entrance point of 15-Khordad Street (Galubandak Crossroads) and the chaotic status of movements: interferences of pedestrians and different-scale vehicles and the subsequent over-crowdedness (Source of the base map: Ref. [33]; source of the diagram and images: Author, 2019-2020) 
As the diagram (Figure 20) shows, 15-Khordad Street is mainly pedestrian-based. However, in specific points of this street, some vehicles can be found. While the paved path represents the orientation of pedestrians and human scale, the presence of parked or in-use motorcycles shows the entrance possibility of vehicles to this area. In other words, the whole scope of the $1-\mathrm{km}$ car-free path of 15 -Khordad Street is not fully preventive of the entrance of vehicles. Insufficient legal bounds in the current legislations and rules on one hand, and the lack of physical preventive elements to the entrance of non-pedestrians, on the hand, have resulted in occasional entrance or movement of motorcycles in this path. The numbers of vehicles associated to Pictures 14, 17 and 26 in the diagram above (Figure 21) and their images (Figure 22) are presented here to further clarify the point.

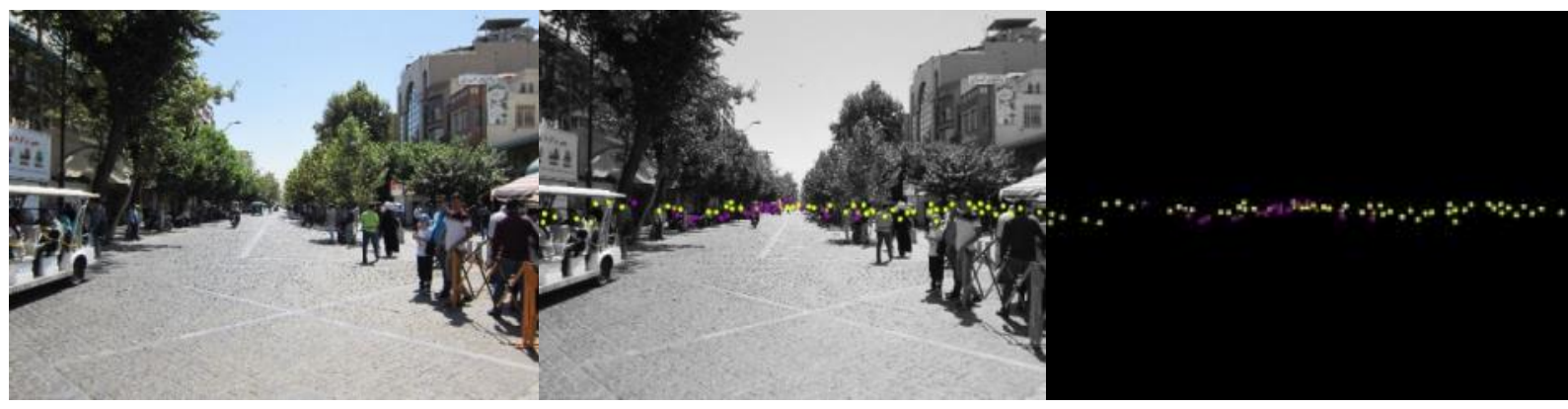

Figure 20. The process of dot-based analysis according to the use of vehicles - Example (yellow dots: pedestrians; violet dots: vehicles; gradient violet-yellow: people in vehicles) (Source: Author, 2019-2020)

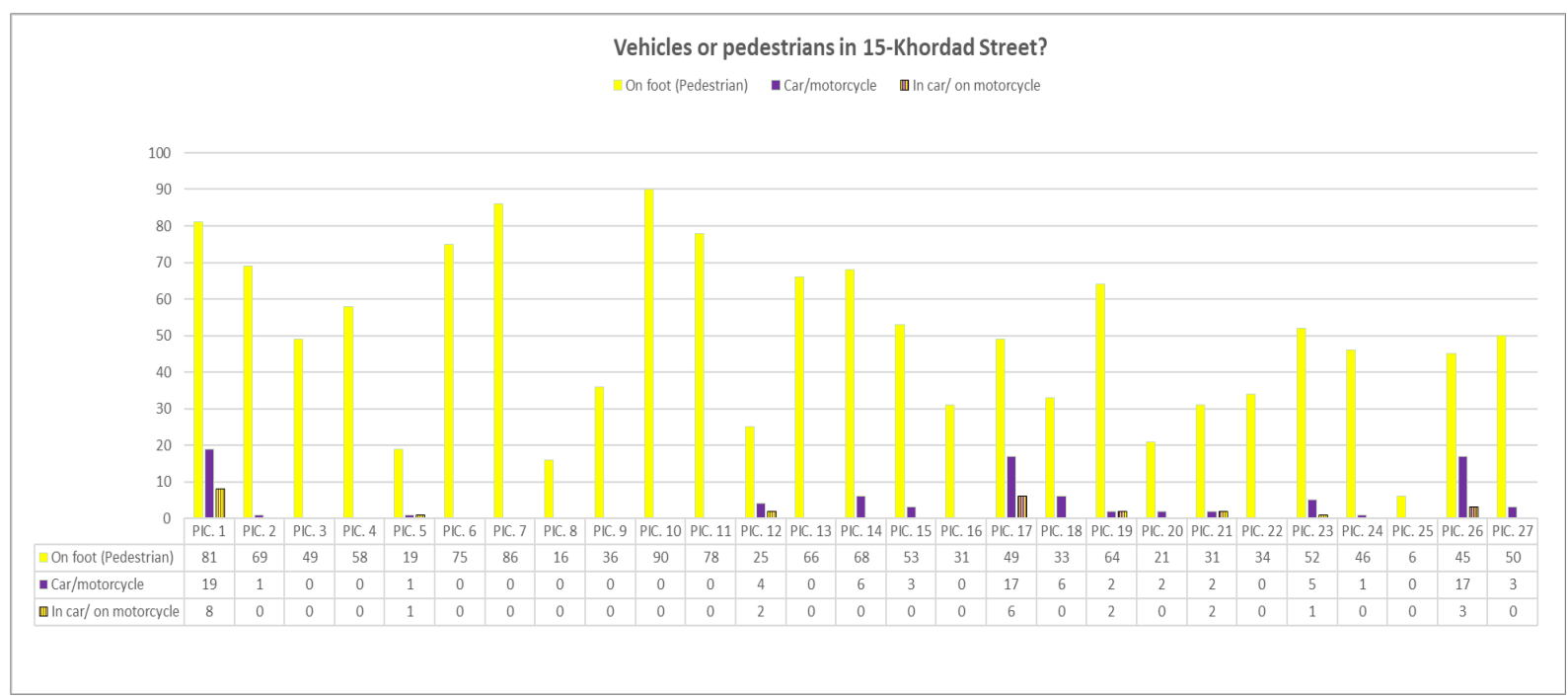

Figure 21. Vehicle or pedestrian orientation in 15-Khordad Street? (Source: Author, 2019-2020) 

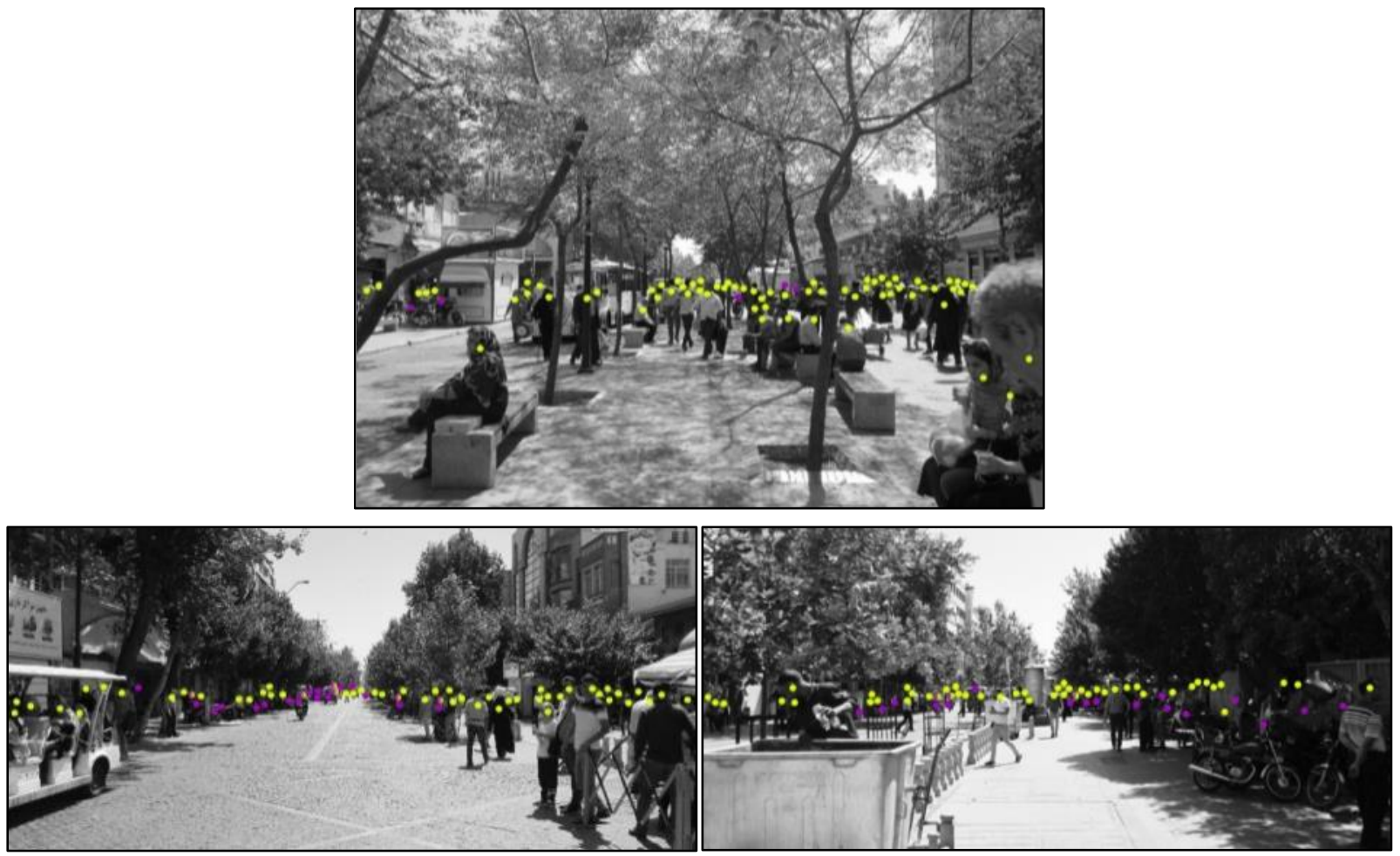

Figure 22. The possibility of the entrance of cars or motorcycles in 15-Khordad Street (Pics. 14, 17 and 21 associated to the Figure 21) (yellow dots: pedestrians; violet dots: vehicles; gradient violet-yellow: people in vehicles) (Source: Author, 2019-2020)

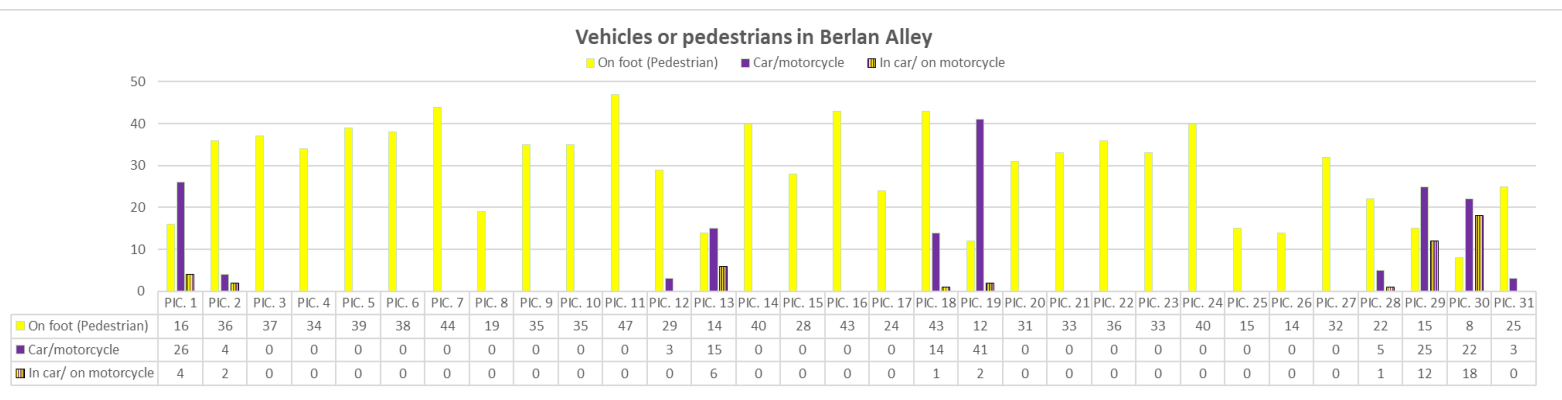

Figure 23. Vehicle or pedestrian orientation in Berlan Alley? (Source: Author, 2019-2020)

\subsection{Accessibility and Mobility in Berlan Alley}

Considering the final point of public transport and the entrance point in Berlan Alley, it should be explained that similar to 15-Khordad Street, in Berlan Alley, the entrance point includes a disorderly status of interferences of pedestrians and vehicles. In comparison to 15 -Khordad Street, however, this street has faced more severe entrance problems as it has three main accesses including the east, middle and west entrance points. This would make the mobility inside this $1.2-\mathrm{km}$ path with the risk of unpredicted crashes particularly in the middle entrance point (intersection of Berlan Alley and Lalehzar Street).

In order to elucidate the specific points with higher numbers of cars/motorcycles in the following figure (Figure 23), explaining the researcher's moving direction through direct observation is necessary. Through the direct appraisal in this research, the moving direction was entering from the middle entrance (Pic. 1: intersection of Berlan Alley and Lalehzar Street), moving to the east end (Pic. 13: intersection of Berlan Alley (also known as Mehran Street) and Sa'adi Street), and returning to the middle entrance (Pic. 19) and then continuing to walk towards the west end (Pic. 30: intersection of Berlan Alley and Ferdowsi Street). As direct observation has revealed, while the eastern and western entrance points incorporate the public transport access to this alley, the middle one mainly includes the interferences of motorcycles who work in Lalehzar Street ${ }^{8}$. For the exact location of east entrance (from Sa'adi Street), middle entrance (from Lalehzar Street), and west entrance (from Ferdowsi Street) please see Figure 6. The following images (Figures 24 and 25) graphically compare these three entrances to Berlan Alley. 


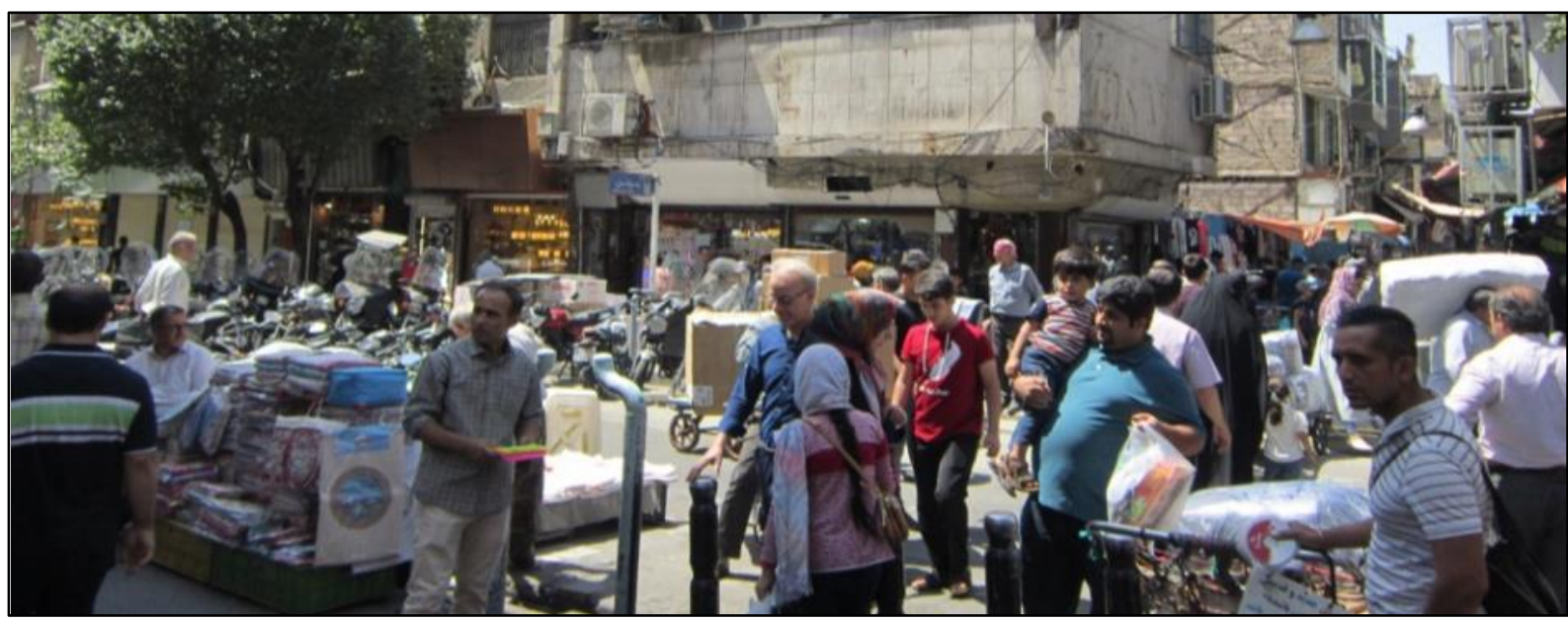

Figure 24. The entrance of Berlan Alley from Lalehzar Street (middle entrance) and the interferences of pedestrians and vehicles particularly the motorcycles working for tools/services shops of Lalehzar Street (Source: Author, 2019)
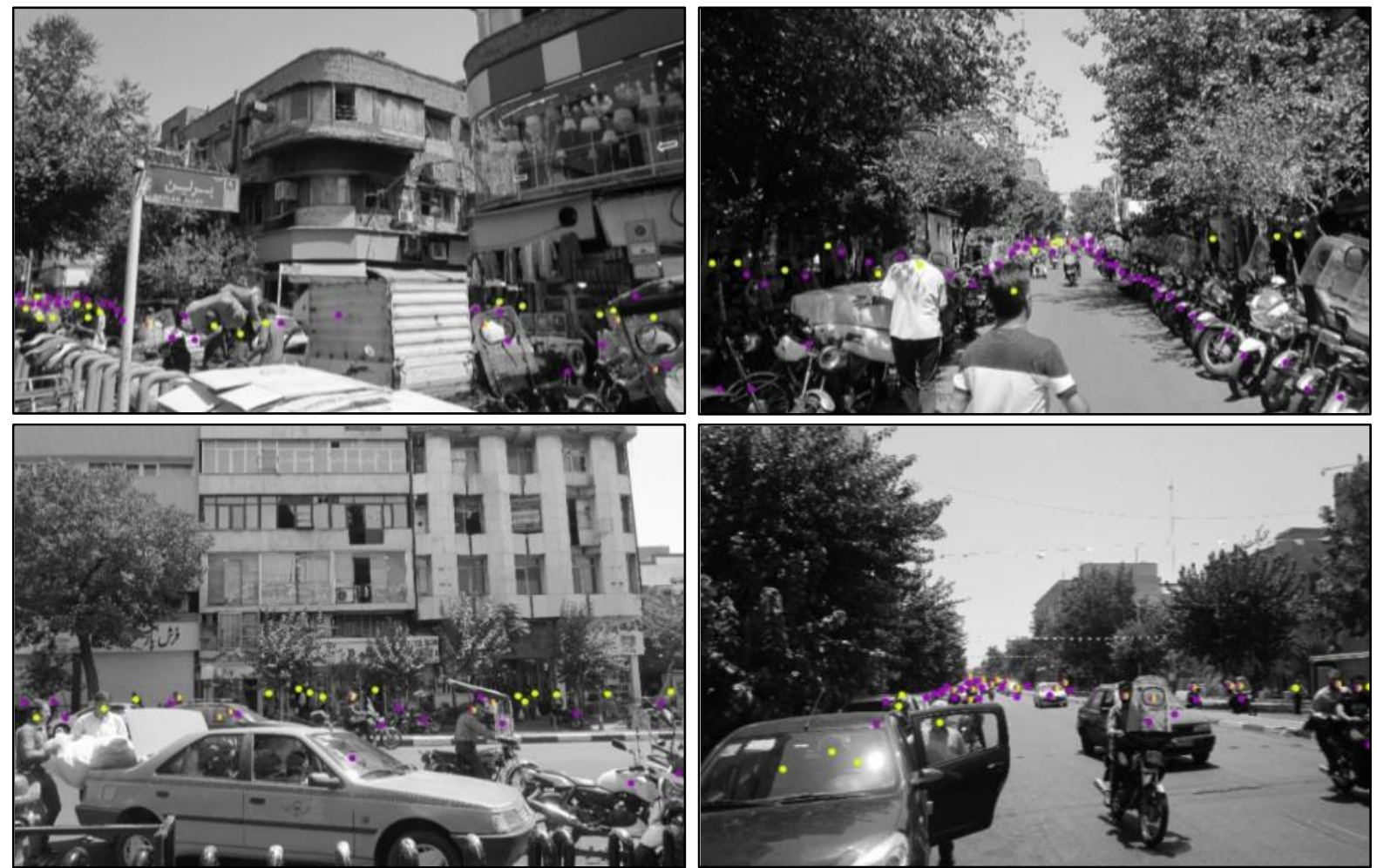

Figure 25. A comparison of all entrances of Berlan Alley and the presence of pedestrians and vehicles: (Top and middle 1 images) The intersection of Berlan Alley and Lalehzar Street (middle entrance); (middle 2) intersection of Berlan Alley (also known as Mehran Street) and Sa'adi Street (east entrance); (bottom) intersection of Berlan Alley and Ferdowsi Street (west entrance) (Source: Author, 2019-2020)

Considering the mobility inside this street by investigating the meaning of car-free —whether as an absolute prohibition or as a limited entrance of vehicles in this street - through direct appraisal has revealed that, in contrast to 15-Khordad Street, the whole area of this path is pedestrian-based excluding the entrance points. As shown in Figure 26, the metal bars as preventive elements for vehicles at the entrances have made this street pedestrian-oriented with an absolute omittance of cars or motorcycles. In short, despite the entrances, this street has become safe for mobility of all various groups of users. 


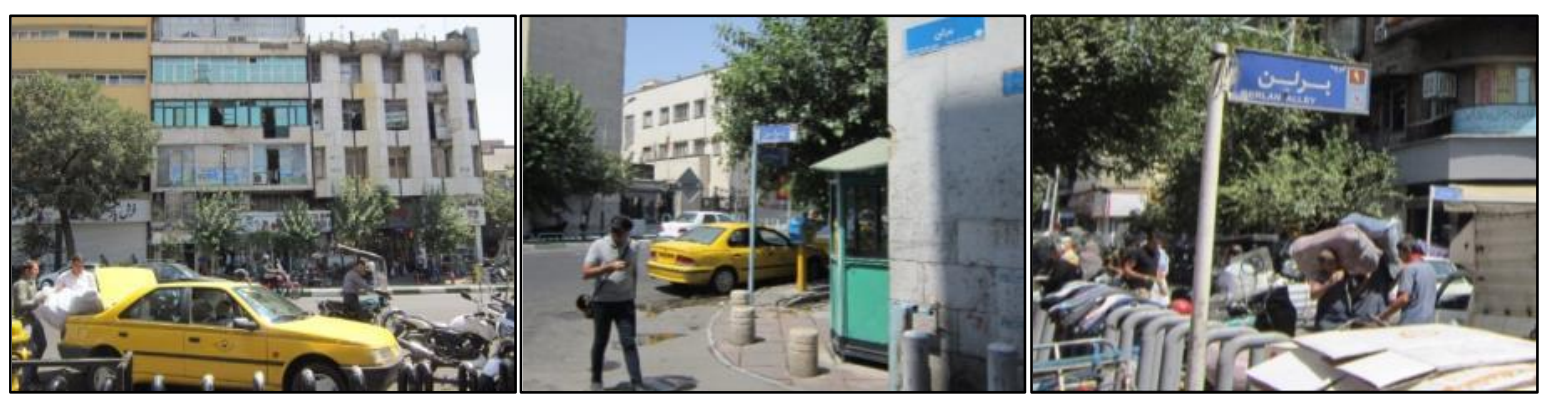

Figure 26. Metal bars as preventive elements of entrance of vehicles to Berlan Alley: (top) east entrance (from Sa'adi Street); (bottom-left) west entrance (from Ferdwosi Street); (bottom-right) middle entrance (from Lalehzar street) (Source: Author, 2019)

10.2. Accessibility and Mobility in Sepah-Salar Street

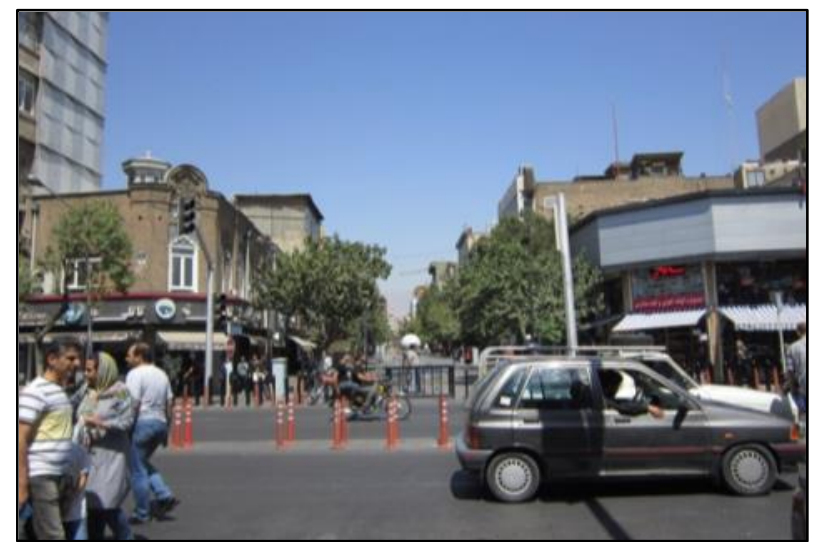

Figure 27. Lower volume of users (less overcrowded-ness) at the entrance point of Sepah-Salar Street in comparison to 15-Khordad Street and Berlan Alley (Source: Author, 2019)

Considering the final point of public transport and entrance of the Sepah-Salar street, it should be explained that similar to the two previous case studies of 15-Khordad Street and Berlan Alley, the entrance of Sepah-Salar Street has not been properly designed and planned and thus include a chaos of pedestrians and different-scale vehicles. In contrast to the two previous streets, however, there is a significant distance between the nearest public transport stops and the entrance point of this street. As a result, the overcrowded-ness -also known as the volume of visitors - is less in the entrance point in comparison to the previous two case studies. Figure 27 further clarifies this point. It should be noted that the nearest stops of bus and line-based taxis are located in two squares called Sa'adi and Baharestan (for further details about the location of these two squares and their distances to Sepah-Salar Street please see Figure 6).

Considering the meanings of car-free and mobility in this street, it should be explained that this street includes certain similarities to each of the two previous streets. Quite similar to 15-Khordad Street, for instance, it includes one main entrance from a main street called Jomhouri (please see Figure 6 for further details). As a result, there are no interferences of pedestrians and vehicles occurring in any middle entrances. Very similar to Berlan Alley, moreover, it has metal bars that act as preventive elements to the entrance of motorcycles or cars at this main entrance. Integration of these two features has made this street completely pedestrian-based with an absolute elimination of cars and motorcycles. The omittance of vehicles in Sepah-Salar Street can also be perceived from the following diagram (Figure 28).

As a result of these two features, pedestrians who access Sepah-Salar street via public transport from the final (nearest) stops in Sa'adi or Baharestan Squares face two extremely opposite images of the concept of a street. Physically separated via the metal bars at the entrance, these two warring images include the vehicle-based street of Jomhouri and the pedestrian-oriented street of Sepah-Salar. While they walk to access this street from any of the two above-mentioned squares, there are no transit or passage phase between Jomhouri and Sepah-Salar Streets. The following two images of these two streets in Figure 29, best represent this fissure of scale. This would thus make a drastic and leaping stride in the users' minds experiencing their City Centre. The lack of this transit phase might need to be reflected in future design and planning for the City Centre in order to achieve pleasant experiences for citizens [40]. 


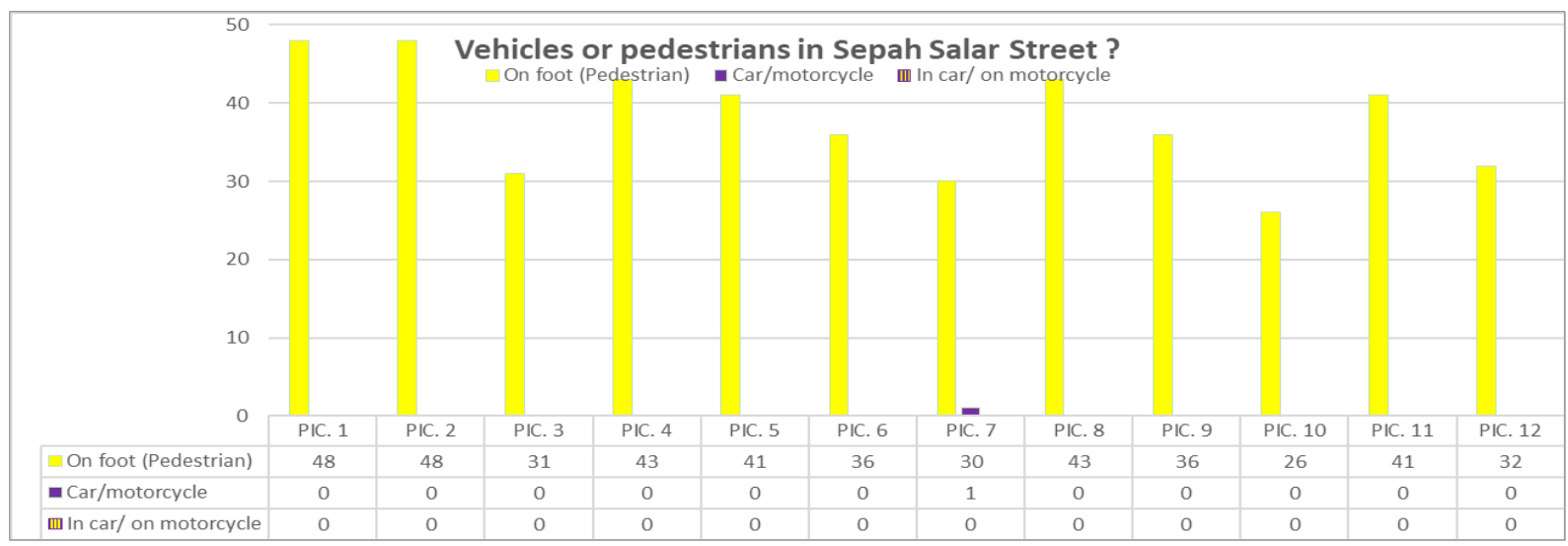

Figure 28. Vehicle or pedestrian orientation in Sepah-Salar Street? (Source: Author, 2019-2020)
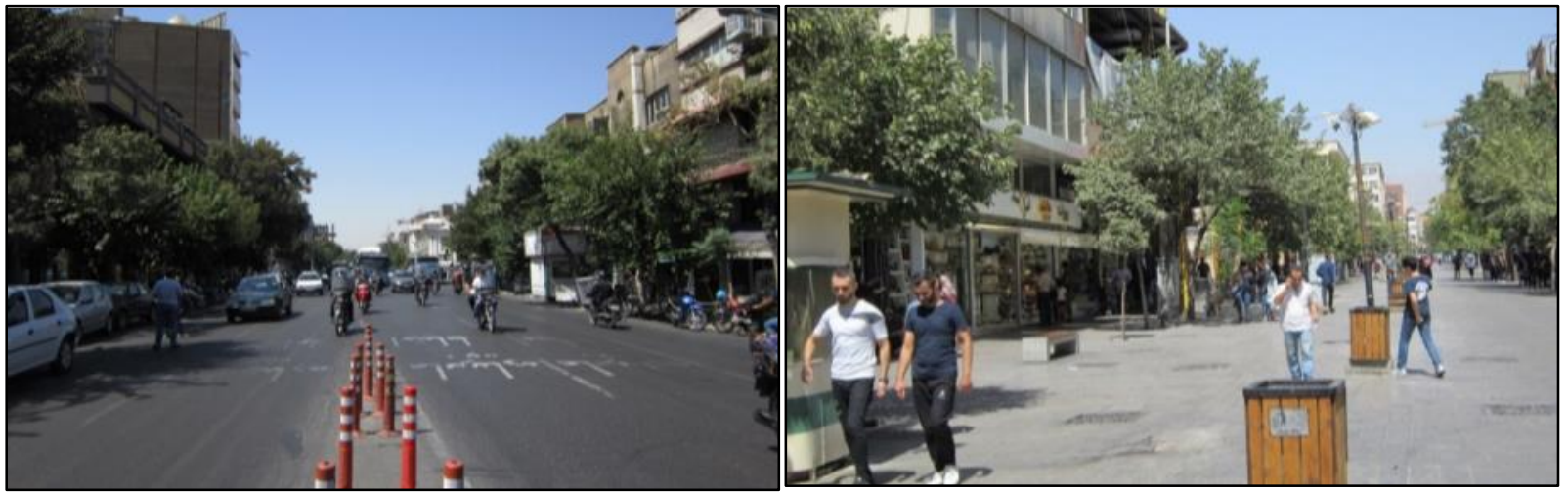

Figure 29. A fissure in the experience of users about the meaning of street: (top) Jomhouri Street as the mainly vehicle-based access via Sa'adi Square; (bottom) Sepah-Salar Street as a pedestrian-based path (Source: Author, 2019)

\section{Conclusions and Future Steps}

Inclusiveness has been defined from different perspectives and in various fields of studies so far. It can be defined as an approach that is "listening to the voices of people concerned and understanding what makes a city liveable to them. This includes the views of women, ... elderly and those with disabilities" [41, p.103]. As this short quote depicts, inclusiveness and the concept of publicness are quite interconnected. Madanipour [39] explains about the challenges in interpreting to the notion of public "either as a society subdivided into tribes and interest groups, or to try to expand the notion of public so as to include all citizens equally" [39, p.9]. To this end, the paper has focused on pedestrians as a whole while appreciating the differences of the formative sub-groups of age-gender. In other words, this research has investigated how, the city centre of Tehran - and in particular its "shopping-recreational-pedestrian"-based paths as public spaces - currently and potentially performs as an inclusive platform for pedestrians that can create physical, mental and spiritual expectations of all age-gender groups of users in an equitable sense.

Tehran, as a city that tops the list of the largest capital cities in the world nowadays, started to grow as the capital since 1794. Transformation of the old ramparted city into an ever-expanding city at the present time has been significantly accelerated by modernisation process, and particularly since the advent of automobile in Iran in 1902. Similar to many modernised metropolises or megalopolises worldwide, this process led to domination of vehicles and subsequently the diminishment of pedestrians in urban contexts. The global awareness of the fading of pedestrians, however, has resulted in recent growing upsurge for a revival of the human scale particularly in the recent decades. This re-integration of human scale with design and planning of cities would thus create a balance in the spectrum of scales for cities. With a focus on City Centre of Tehran, this paper aimed to investigate the street network and how the "shoppingrecreational-pedestrian"-based paths could contribute to this re-integration $[3,5,12,13,16,40]$.

In compliance with this reconciliation of scales in the city centre, only few segregated projects can be traced in Central Tehran. In other words, the revival of pedestrians in the city centre of Tehran is in its initial phases and yet to be developed in future decades. The recent project of prioritisation of human scale in the street of 15 -Khordad $(2.8 \mathrm{~km})$ by Municipality of district 12 of Tehran, for instance, and the remaining presence of on-foot movements in Berlan Alley $(1.2 \mathrm{~km})$ and Sepah-Salar 
Street $(0.5 \mathrm{~km})$, clarify the existing short lengths of pedestrian orientation in comparison to the scale of city [3, $5,10-22,31,32,35,38,40]$.

These short paths, however, attract many Tehranians of all around the city to come to their City Centre particularly for shopping-recreational motives on a daily use. In order to study this common status of the three pedestrian-based case study streets, the applied methodology comprised a literature review, direct appraisal, photography and dot-based analysis. With a focus on the three latter methods, this investigation was mainly carried out in three consecutive usual week days in September 2019 throughout the timespan of 10 a.m. - 4 p.m. The qualitative-quantitative analyses have revealed the existing opportunities and problems in these case study streets in the way to achieve inclusive, healthy, safe, convivial and sustainable City Centre. Accordingly, scale (mental and spatial), age and gender, and speed (accessibility and mobility) have been investigated individually and collectively to provide the possibility of comparison.

The $2.8-\mathrm{km}$ recently pedestrianised street of 15-Khordad is located adjacent to the Grand Bazaar of Tehran. Its proximity to Grand Bazaar on one hand, and its application as the main entrance path to the Bazaar, one the other hand, has made it integrated with the whole area of Grand Bazaar. In other words, this pedestrian-oriented path performs as an access path between the nearest vehicular stop (particularly Galubandak Crossroads) and Grand Bazaar. This has thus resulted in high volume of people - both visitors and the people who work - who use this path as transit. In addition, the combination of various shops such as clothes, shoes and bags, fabrics, cafés, junk foods and fruit juices has made this path a suitable urban space to spend longer time of leisure for many Tehranians [3, 33, 35].

Very similar to $15-$ Khordad Street, the 1.2-km alley of Berlan, has been recognised as an interesting shopping destination for many residents of all around the capital since its infancy in approximately 50 years ago. The narrow width of this alley, however, has mainly made it famous as a shopping passage. In contrast to 15 -Khordad Street and Berlan Alley, the 0.5-km Sepah-Salar Street has been identified as a single-category shopping hub particularly for those interested in bags and shoes. Similar to 15-Khordad Street and in contrast to Berlan Alley, the wide width of Sepah-Salar Street and the urban furniture invite people to pause for longer times [3, 33, 40].

Analysing the physical characteristics of these streets and comparing them with the dimension of City Centre -a rectangle of $5 * 5 \mathrm{Sq}^{2}-$ show that these paths physically incorporates small proportions of the street network of City Centre. However, the mental scale of these pedestrianised axes is urban as they attract Tehranians of all around the city through a daily basis. The variety of products (particularly in 15-Khordad Street and Berlan Alley in type, price and quality, on one hand, and recreational facilities such as cafés or urban furniture (particularly in 15-Khordad and Sepah-Salar Streets) have turned these paths into convivial urban spaces for Tehranians. The particular characteristics of these "shopping-recreational-pedestrian"-based paths, however, address various age-gender group of users [3, 33, 36, 40].

Direct observation and the subsequent dot-based analysis in these streets have revealed that in all three case studies, the first two main groups of users are hierarchically men and women who are visitors and those involved in trading. This shows the lack of appropriate interests of children and young adults to accompany their parents or come as groups to spend their leisure time in these streets. In short, the overcrowded-ness and the subsequent mobility difficulties for younger generations, on one hand, and the insufficient variety in "non-shopping"-based facilities, on the other hand, have mainly made these pedestrian-based streets suitable for adults.

It should be noted that in 15-Khordad street, the growing recreational facilities such as the modern electric cars and tramways for short transits or the traditional horse phaetons have started to fascinate a greater number of younger generations. The comparative analysis has also revealed that the proportion of younger generations is strongly higher in Sepah-Salar Street. The direction appraisal has clarified the reason of this point as two-fold. This mainly includes: 1) less over-crowdedness and the subsequent more mobility and feeling of safety in this street in comparison to 15-Khordad Street and Berlan Alley which is the result of "single-category"-orientation in shopping (shoes and bags); and 2) less density in the number and variety of boutiques on the two sides of this street which also highlight the mobility and feeling of safety.

An integration of the two above-mentioned points clarifies that in order to improve the presence of younger generations, it is necessary to add non-shopping recreational facilities, improve the mobility, increase the feeling of safety, and distribute shops in longer lengths by expanding the current shopping paths. This would thus create the physical, mental and spiritual connectivity for children, young adults and adults and consequently contribute to inclusiveness. For further detailed analysis of the comparative ratios in the current status of the case study streets please see Figure 18.

Considering the concept of car-free in direct appraisal of these three paths shows that in order to create safe pedestrian-oriented paths, the entrance and speed of vehicles (such as goods carriers or emergencies) need to be re-defined. The term 'define' here mainly refers to allowance as well as the possibility. At present, the stationary metal bars at the key entrances to these streets prevent the entrance possibility of large vehicles. This, however, has made the transfer of goods with serious 
difficulties for shops. However, the width of 15-Khordad and Sepah-Salar Streets can physically allow the possibility of the entrance of cars. In short, the fixed preventive meal bars need to be substituted by more flexible elements that can allow the entrance of cars in case of an emergency or in specific predetermined time slots for shops deliveries (such as early in the mornings and before the public opening hours of the shops).

Furthermore, the interferences of movements of large-scale vehicles (BRT and normal buses), public and private cars, motorcycles, and pedestrians in the nearest stops to these streets have negatively affected the quality of the overall experiences of Tehranians while coming to these "shopping-recreational-pedestrian"-based path. As a result, accessibility to these streets, and the mobility in the nearest vehicle-based destination points need to be simultaneously studied. In short, the concept of speed - with a particular focus on accessibility and mobilityshould be investigated in three phases in large-scale design and planning process for Central Tehran. This mainly includes: 1) from people's home to the Central Tehran (Tehranians coming from all around the city); 2) in the nearest vehicle-based stop; and 3) inside the pedestrianised paths.

As an additional point, it should be noted that the presence of women in work platform of Iran particularly since the Islamic Revolution in 1979, has passed through various scenarios. Despite all these transformations, however, Central Tehran is now a platform of co-presence of men and women. Although the ratio is not equal, the growing number in presence of women as visitors and salespeople has been revealed through this research particularly in the direct observation. In order to achieve inclusiveness in Central Tehran, the point needs to be investigated in future researches in various fields including urbanism, planning and management, sociology, anthropology, cultural studies and psychology [37, 38].

\section{Footnotes}

1. The term "megalopolis" was first applied for Tehran by Dr Mansour Falamaki in Ref. [42].

2. In this system, used on a slope land with deep flowing water, vertical wells were dug at specific predetermined depths to access the water. This access was required to create a horizontal channel and to dredge the water in this channel. Then, at the exit point, the water was distributed and conducted via predetermined waterways towards specified lands and farms (for further details please see Refs. $[3,13,23-25])$.

3. Also known as Sofara or Amin-ol-Soltan Street [23].

4. Bab-e-Homayoon Street was also called Sardar-e-Almasieh, Sardar-e-Arq or Dalan-e-Behesht $[3,16]$.
5. It should be noted that, at present, Norouz is identified as the Iranian New Year at the spring equinox. However, in the ancient world of Iran, the New Year was not recognised as Norouz. Rather, Norouz was the celebration of the spring equinox, and according to the Persian calendar the New Year was at another time of the year. As explained by Razi [43] in 2004, in the time of the Achaemenid empire (550 BC-330 BCE), one of the most important dynasties of Iran, the Persian New Year was first held at the time of the autumn equinox and was recognised as Mitrakan or Mehregan. Later, as a result of the cooperation and agreement of multiple groups with various religious beliefs, an eclecticism-based calendar was created. Based on this calendar (also known as Jalali calendar), the Persian New Year was transferred to the spring equinox $[43,44]$.

6. Line-based taxis are a significant part of public transport system in Iran. This system is comprised of taxis on predetermined paths defined by Bus and Taxi Organization of each cities of Iran. Each taxi mainly carries four passengers with virtually identical or en route starting points and destinations.

7. Some colours (categories of users) are not included in this particular image. However, the colour-legend applies to all images and thus need to incorporate all groups of users in the whole area of these streets.

8. Lalehzar street is currently famous mostly as a domestic-to-massive electrical hub for Tehranians. Before the Islamic revolution in 1979, however, this street was recognised as a recreational modern haunt with restaurants, cafés, bars and cinema $[3,6]$.

\section{REFERENCES}

[1] Gehl J., Svarre B., "How to Study Public Life (Translation by Karen Ann Steenhard)", Washington, Island Press/Center for Resource Economics, 2013.

[2] Gehl J., "Cities for People”, Washington, Island Press, 2010.

[3] Behzadfar M., "Case-Study: Tehran, The Identity of City", Tehran, Nashr-e-Shahr, 2007.

[4] Paumier C., "Creating a Vibrant City Center: Urban Design and Regeneration Principles", Washington, The Urban Land Institute, 2004.

[5] Municipality of Tehran, "Living in Tehran: About Tehran", Municipality of Tehran,http://www.tehran.ir/Default.aspx?t abid=117 (accessed Jan. 5, 2020)

[6] Finn J. A., "Getting a PhD: An Action Plan to Help Manage Your Research, Your Supervisor and Your Project”, London, Routledge, 2005.

[7] Hart Ch., "Doing a Literature Search: A Comprehensive Guide for the Social Sciences", $2^{\text {nd }}$ ed., London, SAGE 
Publications Ltd, 2018.

[8] Langmann S., Pick D., "Photography as a Social Research Method”, Singapore, Springer, 2018.

[9] John P., "29 Quotes By Photographer Henri Cartier Bresson”, Caponigro Arts, https://www.johnpaulcaponigro.com/blog/ 12018/29-quotes-by-photographer-henri-cartier-bresson/ (accessed May 7, 2020)

[10] Statistical Centre of Iran, "Tehran Province's Proportion in Population of the Whole Country", Statistical Centre of Iran, https://www.amar.org.ir/news/ID/2648/166 (accessed March 10, 2018)

[11] Anvar A., "Preface", In Norouzi Talab, H. R., eds., Tehran (Past \& Present): The Heritage of Old Tehran, Tehran, Yassavoli Publications, 2011, pp. 12-40.

[12] Madanipour A., "Tehran: The Making of a Metropolis", Chichester, John Wiley, 1998.

[13] Hamidi M. et al., "Structure of Tehran", Tehran, Technical and Engineering Consulting Organization of Tehran, 1997.

[14] Statistical Centre of Iran, "Country's Population and the Excel Chart Categorisation Based on Gender Indicator in Urban and Rural Areas of Iran's Provinces in 2017”, Statistical Centre of Iran, https://www.amar.org.ir/ سرشمارى-عمومى-نفوس-و -مسكن/نتايج-سرشمارى/نتايج-كلى_سرشمارى1395 (accessed Jan. 25, 2020).

[15] Qazvini Z., "Issues of Lands and News of People ( آثار البلاد و Translated from Arabic to Persian by J. Mirza Qajar, and Revised and Complemented by M.H. Mohaddes (1994)", Tehran, Amir Kabir, 1275.

[16] Banimasoud A., "Iranian Contemporary Architecture", $2^{\text {nd }}$ ed., Tehran, Honar-e-Memari-e-Gharn, 2009.

[17] Beytooteh Group, “The History of Iran”, Beytooteh Group, http://www.beytoote.com/art/negah-gozashte/iran-history.ht $\mathrm{ml}$ (accessed Feb. 14, 2014).

[18] Sadvandian S., "The Story of Modernity in Iran", Institute for Iranian Contemporary Historical Studies - The Section about Transformation of Tehran, http://www.iichs.ir/News1/(1) (accessed Apr. 17, 2014).

[19] Dubeux L.,"La Perse”, Paris, Firmin Didot Frères, 1841.

[20] Flandin E., Coste, P., "Voyage en Perse de mm. Eugène Flandin, peintre, et Pascal Coste, architecte, entrepris par ordre de $\mathrm{m}$. le ministre des affaires étrangères, d'après les instructions dressées par l'Institut. Publié sous les auspices de m. le ministre de l'intérieur", Paris, Gide et J. Baudry, 1851-1854 (Approximate).

[21] The New York Public Library (Digital Collection), "Paintings by Flandin and Coste, Derived of the book: Voyage en Perse de mm. Eugène Flandin, peintre, et Pascal Coste, architecte, entrepris par ordre de $\mathrm{m}$. le ministre des affaires étrangères, d'après les instructions dressées par l'Institut. Publié sous les auspices de m. le ministre de l'intérieur", The New York Public Library, https://digitalcollections.nypl.org/collections/voyage-en-per se-de-mm-eugne-flandin-peintre-et-pascal-coste-architecteentrepris? format $=\mathrm{html} \& \mathrm{id}=$ voyage-en-perse-de-mm-eugneflandin-peintre-et-pascal-coste-architecte-entrepris\&per_pa $\mathrm{ge}=250 \&$ page $=2 \# / ? \mathrm{tab}=$ about $\&$ scroll $=33$ (accessed Mar. 24, 2016).
[22] Kiani M., "Transformation of Concepts and Formation of a New 20-Year old Contemporary Architecture (1921-1941)", Tehran, Institute for studies of Iran's contemporary history, 2004.

[23] Keramati G., "The Role of Water in Iranian City (Past and Present)", In: Proceedings of the Third Conference of Architecture History and Urbanism of Iran, Bam, Kerman, 25-29 Mar. 2006, pp. 275-304.

[24] Shieh E., "City and Region in Iran", $6^{\text {th }}$ ed., Tehran, Iran University of Science and Technology (Elm-o-Sanat), 2009.

[25] Maleki A., Khorsandi Aghaei A., "Qanats in Iran: The Case Study of Tehran Qanats", Tehran, Urban Processing and Planning Institute of Tehran (Affiliated to Municipality of Tehran), 2005.

[26] Shahrefarang Group, "Alaoddoleh Street in Tehran in the Year 1910", Shahrefarang Group, http://shahrefarang.com/t ehran-ferdowsi-avenue/ (accessed Sep. 26, 2015)

[27] Javaherkalam A. A., "The History of Tehran", Tehran, Manouchehri Library Publications, 1978.

[28] Shahri J., “Old Tehran”, Tehran, Moein, 1992.

[29] Eshia Organization, "Bab-e-Homayoon Street in Old Tehran”, Eshia Organization, http://images.lib.eshia.ir/imag es/books/23019/madkhal_66_1_1249619103.jpg (accessed Jan. 25, 2015).

[30] Zaka Y., Semsar M. H., "Tehran in Illustration (Volume 1 and 2)", Tehran, Soroush, 1990.

[31] Soltanzadeh H., "Urban Spaces in the Historical Texture of Iran", $3^{\text {rd }}$ ed., Tehran, Cultural Research Bureau of Iran, 2007.

[32] Urban Planning and Architecture Vice-Directorate of Ministry of Roads and Urban Development (under the research of Jahanshah Pakzad), "Design Guidance for Urban Spaces of Iran", Tehran, Shahidi Publications (Ministry of Roads and Urban Development - Urban Planning and Architecture vice-directorate), 2008.

[33] Google Maps, "Tehran, Iran (detail) Map”. Google Maps, https://www.google.co.uk/maps/@35.6835556,51.3790918, $11 \mathrm{z}$ (accessed Nov. 14, 2019)

[34] Department of Transportation \& Traffic of Municipality of Tehran, "Congestion Zone of Tehran: restrictions and fees", Municipality of Tehran, https://my.tehran.ir/ (accessed Oct. 20, 2019)

[35] Keikha A., "Where is 15-Khordad Street?", Kojaro Touristic Group, https://www.kojaro.com/2016/8/13/121188/where-is-15kho rdad-street/ (accessed Aug. 24, 2016)

[36] Momtaz News, "Congestion Zone of Tehran: Map and details”, Momtaz News, http://www.momtaznews.com/

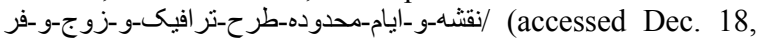
2019)

[37] Fathi N., "The Lonely War: One Woman's Account of the Struggle for Modern Iran”, New York, Basic Books, 2014.

[38] Kian-Thiebaut A., "Women and the Making of Civil Society in Post-Islamist Iran”, In: Hooglund, E., eds., Twenty Years 
of Islamic Revolution: Political and Social Transition in Iran Since 1979, New York, Syracuse University Press, 2002, pp. 56-73.

[39] Madanipour A., "Introduction", In: Madanipour A., eds., Whose Public Space?: International Case Studies in Urban Design and Development, Abingdon, Routledge, 2010, pp. $1-16$.

[40] Municipality of district 12 of Tehran, "About the District 12 of Tehran: Introduction, History and Features", Municipality of district 12 of Tehran (Affiliated to Municipality of Tehran), http://region12.tehran.ir/Default.aspx?tabid=150 (accessed Nov. 24, 2019)

[41] Townsend M., "Men Shouldn’t decide Everything: Women and the Public Realm", In: Moor M. and Rowland J., eds., Urban Design Futures, London, Routledge, 2006, pp. 100-105.

[42] Falamki M. M., "In Conversation with Dr. Falamaki about Tehran”, BBC Persian-Section of Iran, http://www.bbc.co m/persian/iran/story/2007/07/070706_ka-tehran-falamaki.s html (accessed Dec. 20, 2007)

[43] Razi H., “Ancient Iranian Festivals: Norouz, Abpashan, Abrizgan with the Religious Ceremonies and Customs of Zarathushtrian/Parses", Tehran, Behjat, 2004.

[44] Waters M. W., “Ancient Persia: A Concise History of the Achaemenid Empire, 550-330 BCE”, New York, Cambridge University Press, 2014. 